\title{
Buckling of stainless steel columns and beams in fire
}

\section{$\mathrm{K} \mathrm{T} \mathrm{Ng}{ }^{\mathrm{a}}$ and L Gardner}

\author{
${ }^{a}$ Research student. Department of Civil and Environmental Engineering, Imperial College London, \\ South Kensington Campus, London, SW7 2AZ, UK \\ ${ }^{\mathrm{b}}$ Lecturer. Department of Civil and Environmental Engineering, Imperial College London, South \\ Kensington Campus, London, SW7 2AZ, UK (Corresponding author)
}

\begin{abstract}
Material properties and their response to elevated temperatures form an essential part of structural fire design. At elevated temperatures, stainless steel displays superior material strength and stiffness retention in comparison to structural carbon steel. Although independently important, the relationship between strength and stiffness at elevated temperature also has a significant influence on the buckling response of structural components. This paper examines existing test results and presents the results of a numerical parametric study, using ABAQUS on stainless steel columns in fire. Sensitivity to local and global initial geometric imperfections, enhancement of corner strength due to cold-work and partial protection of the column ends is assessed. Parametric studies to explore the influence of variation in local crosssection slenderness, global member slenderness and load level are described. Test results are compared with the current design rules in Eurocode 3: Part 1.2, the Euro Inox/ SCI Design Manual for Structural Stainless Steel and those proposed by CTICM/ CSM. The results of a total of 23 column buckling fire tests, 6 stub column fire tests and 6 fire tests on beams have been analysed. Overly conservative results and inconsistencies in the treatment of buckling phenomena and the choice of deformation limits are highlighted. A revised buckling curve for stainless steel in fire, consistent strain limits and a new approach to cross-section classification and the treatment of local buckling are proposed. These revisions have led to a more efficient and consistent treatment of buckling of stainless steel columns and beams in fire. Improvements of $6 \%$ for column buckling resistance, $28 \%$ for stub column (crosssection) resistance and $14 \%$ for in-plane bending resistance over the current Eurocode methods are achieved.
\end{abstract}




\section{Keywords}

Beams, buckling, columns, elevated temperature, EN 1993-1-2, Eurocode 3, fire, stainless steel, structures

\section{Introduction}

Of primary importance in the design of structures for the accidental situation of fire exposure is to preserve the load bearing function of the structure and to avoid premature collapse whilst occupants evacuate and fire-fighters operate. Metallic structures are typically more vulnerable to the effects of fire than timber or reinforced concrete structures, because of the relatively rapid temperature development in the structural members, owing primarily to their high ratio of surface area to volume and the high thermal conductivity of the material. The relatively low probability of the occurrence of fire is reflected by the use of reduced partial safety factors in design.

The subject of steel structures in fire has received increasing attention in recent years. General background information related to the behaviour of steel structures at elevated temperatures and guidance on design for fire safety may be found in [1] and [2]. Notable recent advances in understanding in this area have evolved, in particular, from observations and subsequent analyses of the full-scale Cardington fire tests [3], performed in the mid-90s. The importance of structural continuity [4, 5] and membrane action in composite floors [6], for example, is now widely accepted. Stainless steel structures in fire have received less attention, principally due to the relatively limited use of stainless steel in structural engineering applications to date. The use of stainless steel in structural and architectural applications is however growing due, in part, to the material's attractive appearance, corrosion resistance, ease of maintenance, low life cycle costs and fire resistance, alongside improved and more widespread design guidance and enhanced product availability [7].

At elevated temperatures, stainless steel offers better retention of strength and stiffness than structural carbon steel, due to the beneficial effects of the alloying elements. This behaviour is reflected in EN 1993-1-2 (2005) [8], as shown in Figs. 1 and 2. The strength reduction factors shown in Fig. 1 are for grade 1.4301 (304) 
austenitic stainless steel, the most widely adopted grade for structural applications, whereas the stiffness reduction factors of Fig. 2 are common to all grades. Strength reduction factors are defined at two strain levels: $k_{2, \theta}$ is the elevated temperature strength at $2 \%$ total strain $f_{2, \theta}$, normalised by the room temperature $0.2 \%$ proof strength $f_{y}$, whilst $k_{0.2 p, \theta}$ is the elevated temperature $0.2 \%$ proof strength $f_{0.2 p, \theta}$, normalised by the room temperature $0.2 \%$ proof strength $f_{y}$. The stiffness reduction factor $\mathrm{k}_{\mathrm{E}, \theta}$ is defined as the elevated temperature initial tangent modulus $\mathrm{E}_{\theta}$, normalised by the initial tangent modulus at room temperature $\mathrm{E}_{\mathrm{a}}$. Other thermal properties, including those which influence temperature development are discussed in [9]. It is worth noting that the minimum specified room temperature $0.2 \%$ proof strength $f_{y}$ for the most common structural grades of austenitic stainless steel typically ranges between 210 and $240 \mathrm{~N} / \mathrm{mm}^{2}$, whilst the Young's modulus is $200000 \mathrm{~N} / \mathrm{mm}^{2}$ [10].

As detailed in section 5, in addition to knowledge of the independent degradation of material strength and stiffness at elevated temperatures, the relationship between strength and stiffness is also important, since this defines susceptibility to buckling. For structural stainless steel design, this concept is included in codes for member buckling, though not for local plate buckling (or cross-section classification). This inconsistency is addressed herein.

\section{Review of fire tests on structural stainless steel members}

A number of recent experimental studies of the response of unprotected stainless steel structural members exposed to fire have been performed. All tests are summarised in this section, and utilised later for comparison with existing design methods and for the development of revised design provisions. A selection of the tests is replicated numerically in section 3 of this paper, forming the basis for parametric studies.

Fire tests on a total of 23 austenitic stainless steel columns [11,12,13,14,15] (where failure was by flexural buckling), 6 stub columns [16] and 6 laterally-restrained beams $[11,12,15]$ have been reported. A summary of the tests is provided in Tables 1,2 and 
3. Nominal section sizes, cross-section classifications, boundary conditions, applied loads and critical temperatures have been tabulated. Those tests in Table 1 marked with superscript ' $a$ ' or ' $b$ ' were reported in most detail and have been used to validate the numerical models, as described in the following section of this paper.

Of the 23 column buckling tests detailed in Table 1, 4 had fixed boundary conditions whilst the remainder were pin-ended. All column buckling tests were performed on hollow sections (19 rectangular hollow sections (RHS) and 3 circular hollow sections (CHS)) with the exception of one I-section, made up of a pair of channel sections welded back-to-back. The 6 stub column tests given in Table 2 were all Class 4 rectangular hollow sections. The 6 beam tests summarised in Table 3 included one rectangular hollow section, 3 I-sections and 2 top-hat sections. All of the tested beams were supporting a concrete slab which provided full lateral restraint. There have been no tests on laterally unrestrained stainless steel beams in fire. All tests were anisothermal, whereby the load was held at a constant level and the temperature was increased (generally following the standard fire curve of ISO 834-1 (1999) [17]) until failure.

\section{Numerical modelling}

\subsection{General}

A numerical modelling study was performed to gain further insight into the buckling response of stainless steel compression members in fire, and to investigate the influence of key parameters. The finite element software package ABAQUS [18] was employed throughout the study. Analyses were conducted to simulate 12 column buckling fire tests (as indicated in Table 1): 4 fixed-ended and 2 pin-ended columns reported in [11, 12], and 6 pin-ended columns reported in [13]. Subsequent sensitivity studies were performed to investigate the influence of local and global initial geometric imperfections, cold-worked corner material properties and partial protection of the column ends. Parametric studies were conducted to assess variation in local crosssection slenderness, global member slenderness and load level. 
The stainless steel members were modelled using the shell elements S4R, which have 4 corner nodes, each with 6 degrees of freedom, and are suitable for thick or thin shell applications [18]. A mesh convergence study was performed to identify an appropriate mesh density to achieve suitably accurate results whilst maintaining practical computation times. Models with a range of mesh sizes from two to ten elements across the cross-section width yielded very similar results. Five elements across each plate width and an aspect ratio of close to unity (defining mesh size in the length direction) were adopted. Test boundary conditions were replicated by restraining suitable displacement and rotation degrees of freedom at the column ends, and through the use of constraint equations.

The fire tests described in section 2 of this paper were performed anisothermally. This was reflected in the numerical modelling by performing the analyses in two steps: in the first step, load was applied to the column at room temperature, and in the second step, temperature was increased following the measured temperature-time relationships until failure. It should be noted that the RHS $40 \times 40 \times 4$ test specimens reported in [13] did not follow the standard fire curve of ISO 834-1 [17]; instead, a bespoke, bi-linear temperature-time relationship was used - this relationship was also included in the numerical study by employing the measured temperature-time data [13].

\subsection{Material modelling}

Material modelling represents one of the most important aspects of a FE simulation. Inappropriate definition of material behaviour will significantly hinder the ability of a model to replicate observed structural response. In the present study, material modelling was based on a multi-linear fit to measured elevated temperature stressstrain data. The measured stress-strain curves of Ala-Outinen and Oksanen [13] were rather erratic, particularly at low strains, with regions where increasing strain was met with increasing stiffness. Thus in order to smooth the stress-strain relationship, a compound Ramberg-Osgood formulation was used to represent the experimental data. The adopted compound Ramberg-Osgood model has been shown to be capable of very accurately representing measured stress-strain data of similar form [19]. The 
measured stress-strain data and corresponding compound Ramberg-Osgood curves for $200^{\circ} \mathrm{C}$ and $600^{\circ} \mathrm{C}$ are shown in Fig. 3.

ABAQUS [18] requires that the material stress-strain relationship is defined in terms of true stress $\sigma$ true and $\log$ plastic strain $\varepsilon_{\mathrm{ln}}^{\mathrm{pl}}$, as defined by Eqs. (1) and (2), where $\sigma$ nom and Enom are engineering stress and strain, respectively and $E$ is Young's modulus.

$$
\begin{aligned}
& \sigma_{\text {true }}=\sigma_{\text {nom }}\left(1+\varepsilon_{\text {nom }}\right) \\
& \varepsilon_{\text {ln }}^{\mathrm{pl}}=\ln \left(1+\varepsilon_{\text {nom }}\right)-\frac{\sigma_{\text {true }}}{E}
\end{aligned}
$$

The material coefficient of thermal expansion was taken from EN 1993-1-2 [8] for all models.

\subsection{Corner material properties}

The mechanical properties of stainless steel are sensitive to the level of cold-work, resulting in the corner regions of cold-formed sections having $0.2 \%$ proof strengths significantly higher than the $0.2 \%$ proof strengths of the flat regions. Failure to allow for these enhanced strength regions in numerical modelling and design leads to under-prediction of load carrying capacity [20], or in the context of the current study, under-prediction of fire resistance.

Based upon tensile tests on material extracted from the corner regions of cold-formed stainless steel cross-sections, expressions for the prediction of the corner material strength have been developed in [21]. It was proposed that the $0.2 \%$ proof strength of the corner material $\sigma_{0.2, c}$ for both roll-forming and press-braking may be approximated by Eq. (3).

$$
\sigma_{0.2, \mathrm{c}}=\frac{1.881 \sigma_{0.2, \mathrm{v}}}{\left(\frac{\mathrm{r}_{\mathrm{i}}}{\mathrm{t}}\right)^{0.194}}
$$


where $\sigma_{0.2, v}$ is the $0.2 \%$ proof strength of the virgin material, $r_{i}$ is the internal corner radius and $t$ is the material thickness. Eq. (3) has been adopted in the present study to predict the corner properties of press-braked sections.

It was also proposed that the ultimate strength of corner material $\sigma_{u, c}$ may be approximated on the basis of the $0.2 \%$ proof strength of corner material, and the $0.2 \%$ proof strength and ultimate strength of the virgin material, $\sigma_{0.2, v}$ and $\sigma u, v$ respectively, as given by Eq. (4). Eq. (4) has been adopted herein to approximate the ultimate strength of corner material $\sigma_{u, c}$

$$
\sigma_{u, c}=0.75 \sigma_{0.2, \mathrm{c}}\left(\frac{\sigma_{\mathrm{u}, \mathrm{v}}}{\sigma_{0.2, \mathrm{v}}}\right)
$$

Test results [22] have indicated that the degradation of strength and stiffness associated with cold-worked material is generally similar to that of annealed material. Strength enhancements associated with cold-work are retained up to about $800^{\circ} \mathrm{C}$, beyond which such enhancements disappear. Thus, the elevated temperature stressstrain properties of the corners have been determined on the basis of the predicted room temperature corner properties and the measured strength and stiffness reduction factors for the flat material.

In addition to the level of strength enhancement in the corner regions due to coldwork, the degree to which the strength enhancement extends beyond the curved corner portions of the section is also important. Numerical studies at room temperature have indicated that the corner strength enhancements extend beyond the curved corner portions to a distance equal to the material thickness for press-braked sections [23] and two times the material thickness for roll-formed sections [20, 23]. In the present investigation, sensitivity studies were carried out on models based on the four $\mathrm{SCl}$ column tests in order to assess the influence of the extent of the enhanced strength corner regions on the fire resistance of stainless steel columns. All four columns were formed by press-braking. Table 4 shows the measured $0.2 \%$ proof strengths of the flat material and the calculated $0.2 \%$ proof strengths of the corner 
material for the modelled columns, and summarises the results of the sensitivity study. Finite element models were generated with (1) no corner strength enhancement (FE), (2) corner strength enhancement in the curved corner portions only $\left(F E_{(c)}\right)$ and (3) corner strength enhancement in the curved corner portions and extending to a distance equal to the material thickness beyond the curved regions $\left(F E_{(c+t)}\right)$. The models contained a global imperfection of amplitude $L / 1000$, where $L$ is the column length. The results generally indicate a progressive improvement in the prediction of test behaviour as the extent of the corner regions is increased. Over-prediction of the fire resistance of the ][ $200 \times 150 \times 6$ (back-to-back channel) section is believed to be due to the poor performance of the tested specimen, as described in [12], rather than particular modelling deficiencies. Clearly the importance of inclusion of the corner strength enhancements will be dependent on the geometry of the sections considered, and in particular the ratio of the corner area to the total cross-sectional area. However, the comparisons of Table 4 indicate that failure to account for the corner strength enhancements will lead to under-prediction of fire resistance of about $5 \%$ $10 \%$.

\subsection{Residual stresses}

The primary effect of residual stresses on the response of the structural components is to cause early yielding of parts of the cross-section, and hence a premature reduction of stiffness. For cold-formed sections, the dominant residual stresses are those induced through plastic deformation during the production process and characterised by through-thickness bending distributions. However, studies [20, 24] have concluded that if the material properties are established from coupons cut from within the cross-section, the effects of these bending residual stress will be inherently present, and do not need to be explicitly defined in the FE model.

In a study reported by Gardner and Nethercot [20] the sensitivity of the stainless steel stub column models to membrane (weld induced) residual stresses was assessed. FE simulations were run with and without residual stresses while other parameters remained identical. The results showed that residual stresses caused a small reduction in stiffness of the stub columns but had little influence on their overall behaviour or ultimate load carrying capacity. Similar conclusions were reached by 
[25]. Given the higher deformations, greater uncertainties and possible stressrelieving effects associated with structural components at elevated temperature, the influence of residual stresses are expected to be negligible and have therefore been ignored in the present study.

\subsection{Geometric imperfections}

All structural members contain geometric imperfections, which can have an important influence on their structural behaviour. Imperfections of the form of the lowest global and local elastic buckling modes were included in the present study. Gardner and Nethercot [20] modelled a series of stainless steel columns at room temperature with global imperfection amplitudes of $L / 1000, L / 2000$ and $L / 5000$, where $L$ is the column length. Comparisons indicated that a global imperfection amplitude of L/2000 provided the best agreement between FE results and test results. In the present elevated temperature study, three global imperfection amplitudes were considered: $\mathrm{L} / 2000, \mathrm{~L} / 1000$ and L/500 were used in the numerical models. The results are shown in Table 5. For the global imperfection sensitivity study, enhanced strength corner properties were included in the curved corner portions of the section only. The comparisons indicate that, as for room temperature column buckling, a global imperfection amplitude of L/2000 also provides good agreement with tests at elevated temperatures. Thus a global imperfection amplitude of $L / 2000$ was employed for the remainder of this study.

A local imperfection was also included in the models to ensure that local plate buckling was not inhibited. Following analysis of measured imperfections in stainless steel hollow sections, Gardner and Nethercot [20] recalibrated a model proposed by Dawson and Walker [26] to give Eq. (5) for the prediction of local imperfection amplitudes $W_{0}$.

$$
w_{0}=0.023 t\left(\frac{f_{y}}{\sigma_{c r}}\right)
$$


where $f_{y}$ is the material $0.2 \%$ proof strength and $\sigma_{c r}$ is the elastic critical plate buckling stress. Sensitivity of the modelled columns to variation in local imperfections was assessed by considering three imperfection amplitudes wo: 0.01t, 0.1t and Eq. (5), where $t$ is the material thickness. The results displayed very little sensitivity to this variation; Eq. (5) was employed throughout the remainder of this study.

\subsection{Protection of column ends}

Four columns, RHS $150 \times 100 \times 6$, RHS $150 \times 75 \times 6$, RHS $100 \times 75 \times 6$ and ][ $200 \times 150 \times 6$, were protected with a mineral fibre blanket up to $200 \mathrm{~mm}$ from each end of the column, leaving an exposed length of $3 \mathrm{~m}$, as indicated in Fig. 4. The influence of this partial protection on the fire resistance of the columns was assessed numerically. The first step was to conduct a heat transfer analysis with the heat applied to the exposed portions of the column only, allowing heat transfer to the protected ends by conduction. The results of the heat transfer analysis were input into the anisothermal non-linear analysis to determine the elevated temperature response of the columns. Thermal material properties were taken as those recommended in EN 1991-1-2 [27] and EN 1993-1-2 [8].

Table 6 compares the results of the FE models with and without protection at the column ends. The models included enhanced strength corner properties extending to a distance equal to the material thickness beyond the curved corner portions, and global imperfection amplitudes of L/2000. The results indicate that the effect of the end protection is to provide a marginal (around $4 \%$ on average) increase in fire resistance. The columns with protected ends investigated in this study had fixed boundary conditions; such columns would be expected to gain more benefit from end protection than pin-ended columns, where the level of stress at the ends would be lower.

\subsection{Parametric studies}

A total of 12 columns were modelled using the non-linear finite element package ABAQUS [18]. A summary of the comparison between test and FE results is given in 
Table 7. A graph comparing typical test and FE lateral deflection versus temperature curves is shown in Fig. 5. Overall, good agreement between FE results and test results has been achieved. The general tendency of the FE models to under-predict the fire resistance of the test specimens may be due to the assumption of constant temperature through the wall thickness of the sections, taken as that measured on the surface of the test specimens (representing an upper bound). The FE model of the back-to-back channel section column performed better than the test. As mentioned previously, this is believed to be due to the poor performance of the tested specimen [12], rather than particular modelling deficiencies. From the comparisons between test and FE results, it may be concluded that the described FE models are capable of replicating the non-linear, large deflection response of stainless steel columns in fire.

Following satisfactory agreement between the test and FE results, a series of parametric studies were performed in order to investigate the buckling response of stainless steel members at elevated temperatures. The parametric study was based upon the tested RHS $100 \times 75 \times 6$ section, and employed the measured material properties throughout the study.

Parametric studies were carried out to examine variation in cross-section slenderness (cross-section classification), overall member slenderness $\bar{\lambda}$ and load ratio. Load ratio was defined as the applied load divided by the room temperature compression resistance, and determined according to EN 1993-1-2 [8].

Variation in cross-section slenderness was achieved by considering a range of crosssection thicknesses. The results of the cross-section slenderness parametric study are shown in Fig. 6. Four cross-section thicknesses were considered, with the corresponding section classification given in brackets: $8 \mathrm{~mm}$ (Class 1), $6 \mathrm{~mm}$ (Class 1), $4 \mathrm{~mm}$ (Class 3 ) and $2 \mathrm{~mm}$ (Class 4). Load ratio was also varied from 0.2 to 0.8 . The design curve calculated from Eurocode 3 for Class 1 to 3 cross-sections and that corresponding to the $2 \mathrm{~mm}$ section thickness (Class 4 ) are also shown in Fig. 6 . The results show that all the Class 1 to 3 sections behave similarly, and generally follow the Eurocode 3 design curve. For the Class 4 sections, however, agreement is poor. The reason for this is two-fold. Firstly, the load ratio is determined by normalising the 
applied load by the room temperature buckling resistance - for Class 4 sections, the room temperature buckling resistance is calculated on the basis of an effective section to account for local buckling; this results in higher load ratios. Secondly, EN 1993-1-2 specifies use of the strength reduction factor corresponding to the $0.2 \%$ proof stress $\mathrm{k}_{0.2 \mathrm{p}, \theta}$ for Class 4 cross-sections, whilst Class 1 to 3 sections benefit from the use of a higher $2 \%$ strain limit and adopt $\mathrm{k}_{2, \theta}$. Comparison with test results and development of improved agreement for Class 4 sections are described in sections 4 and 5 of this paper.

Variation in member slenderness was achieved by considering a range of column lengths. Results of the study are shown in Fig. 7. As anticipated, there is a general trend showing that critical temperature reduces with increasing load ratio. The results also indicate that variation of critical temperature with load ratio is slenderness dependent. This would be expected since stocky columns are controlled primarily by material strength and its degradation, whilst slender columns are controlled primarily by material stiffness and its degradation. Since strength and stiffness do not degrade at the same rate with temperature it follows that the critical temperature of columns is slenderness dependent.

\subsection{Discussion}

This section has described a numerical study of structural stainless steel members in fire. 12 column buckling test results have been replicated numerically and a series of sensitivity and parameters studies to investigate the influence of the key individual parameters have been performed. The principal findings were:

- the non-linear response of stainless steel members in fire can be accurately replicated numerically

- sensitivity to geometric imperfections and residual stresses was relatively low

- inclusion of enhanced strength corner properties increased critical temperatures by about 5\%

- the critical temperature of columns is slenderness dependant (for a given load ratio) 
- Class 4 models performed considerably better than predicted by Eurocode 3

In the following sections, comparisons are made between tests on stainless steel members in fire and existing design guidance. On the basis of the test results, the findings of the numerical study and consideration of the buckling behaviour of structural components, revisions to the existing design guidance are proposed.

\section{Comparison with existing design guidance}

This section presents a comparison of test results with existing design rules proposed by EN 1993-1-2 [8] the Euro Inox/ SCI Design Manual for Structural Stainless Steel [28] and CTICM/CSM [29]. In the comparisons, the measured geometric and material properties are employed and all partial factors are set equal to unity to enable a direct comparison. Calculated Eurocode design resistances in the present paper vary marginally from those given in [12] due to use of updated effective width formulations (to reflect code revisions) and measured ultimate strength, in place of the nominal values employed in [12]. Ultimate strength is required for the determination of the strength reduction factor at $2 \%$ strain $\mathrm{k}_{2, \theta}$.

\subsection{Compression members}

\subsubsection{Eurocode 3: Part 1.2}

From EN 1993-1-2 (2005), the design buckling resistance $\mathrm{Nb,fi,t,Rd}$ at time $\mathrm{t}$ of a compression member with a uniform temperature $\theta$ should be determined from Eq. (6) for Class 1 to 3 cross-sections and Eq. (7) for Class 4 cross-sections.

$$
\begin{array}{ll}
N_{b, f i, t, R d}=\frac{\chi_{f i} A k_{2, \theta} f_{y}}{\gamma_{M, f i}} & \text { for Class 1,2 or } 3 \text { cross-sections } \\
N_{b, f i t, R d}=\frac{\chi_{f i} A k_{0.2 p, \theta} f_{y}}{\gamma_{M, f i}} & \text { for Class } 4 \text { cross-sections }
\end{array}
$$


where $\mathrm{k}_{2, \theta}$ is the elevated temperature strength at $2 \%$ total strain $\mathrm{f}_{2 \%, \theta, \theta}$, normalised by the room temperature $0.2 \%$ proof strength $\mathrm{f}_{\mathrm{y}}$, whilst $\mathrm{k}_{0.2 p, \theta}$ is the elevated temperature $0.2 \%$ proof strength $f_{0.2 p, \theta}$, normalised by the room temperature $0.2 \%$ proof strength $\mathrm{f}_{\mathrm{y}}$. The reduction factor for flexural buckling in fire $\chi_{\mathrm{fi}}$ is given by Eqs. (8) and (9).

$$
\chi_{\mathrm{fi}}=\frac{1}{\varphi_{\theta}+\sqrt{\varphi_{\theta}^{2}-\bar{\lambda}_{\theta}^{2}}}
$$

in which

$$
\varphi_{\theta}=0.5\left(1+0.65 \bar{\lambda}_{\theta} \sqrt{\frac{235}{f_{y}}}+\bar{\lambda}_{\theta}{ }^{2}\right)
$$

where the non-dimensional elevated temperature member slenderness $\bar{\lambda}_{\theta}$ is defined by Eqs. (10) and (11). It is worth noting that the buckling curves defined by Eq. (8) and (9) exhibit no plateau, where design may be based on the cross-section resistance alone.

$$
\begin{array}{ll}
\bar{\lambda}_{\theta}=\bar{\lambda}\left(\mathrm{k}_{2, \theta} / \mathrm{k}_{\mathrm{E}, \theta}\right)^{0.5} & \text { for Class } 1 \text { to } 3 \text { cross-sections } \\
\bar{\lambda}_{\theta}=\bar{\lambda}\left(\mathrm{k}_{0.2 \mathrm{p}, \theta} / \mathrm{k}_{\mathrm{E}, \theta}\right)^{0.5} & \text { for Class } 4 \text { cross-sections }
\end{array}
$$

Cross-sections should be classified as for normal temperature design, but with a reduced value for $\varepsilon$ as given by Eq. (12).

$$
\varepsilon=0.85\left(\frac{235}{f_{y}}\right)^{0.5}
$$

Although it appears to the authors to be inconsistent, Annex E of EN 1993-1-2 (2005) states that effective section properties for Class 4 cross-sections should be determined as for room temperature design (i.e. without incorporating the reduced value for $\varepsilon$ as given by Eq. (12)). Buckling resistance for members with Class 4 cross- 
sections have therefore been determined on the basis of the room temperature effective section properties.

The value of $\varphi_{\theta}$ in Eq. (9) is dependent on the material yield strength, thus the Eurocode 3 buckling curve cannot be graphically compared directly against the column buckling tests. Fig. 8 compares the Eurocode 3 buckling curves with $f_{y}=300$ $\mathrm{N} / \mathrm{mm}^{2}$ and $500 \mathrm{~N} / \mathrm{mm}^{2}$ with all available test results (from Table 1). A numerical comparison of test buckling loads and predicted buckling resistances at the critical temperature is also given in Table 8, revealing a mean Eurocode divided by test resistance of 0.94 , with a corresponding scatter (coefficient of variation, COV) of 0.16 . Numerical comparison of the stub column test and predicted failure loads is given in Table 9, revealing a mean Eurocode divided by test resistance of 0.71 , with a corresponding scatter (coefficient of variation, COV) of 0.13 .

\subsubsection{Euro Inox/ SCI Design Manual for Structural Stainless Steel}

The Euro Inox/ SCI Design Manual for Structural Stainless Steel [28] adopts the room temperature cross-section classification for elevated temperature design, but otherwise follows the Eurocode approach. The $\varepsilon$ factor is defined by Eq. (13).

$$
\varepsilon=\left(\frac{235}{f_{y}} \frac{E}{210000}\right)^{0.5}
$$

Despite the different definition of $\varepsilon$ in the Euro Inox/ SCI Design Manual for Structural Stainless Steel, no change in cross-section classification from that of EN 1993-1-2 results for the considered test data, and hence there is no difference in predicted buckling resistances. The graphical comparison of the column buckling test results with the Euro Inox/ SCI Design Manual for Structural Stainless Steel is therefore the same as that given for EN 1993-1-2 in Fig. 8. The numerical comparisons of test and predicted resistances for column buckling and stub column (cross-section) resistance are shown in Tables 8 and 9 respectively, and display the same results as obtained for EN 1993-1-2. 


\subsubsection{CTICM/ CSM Proposal}

CTICM/ CSM [29] has proposed a number of modifications to the EN 1993-1-2 approach in order to simplify calculations by avoiding the need to determine the elevated temperature strength at $2 \%$ strain, and to improve agreement with test results. Firstly, it was proposed that cross-section classification at elevated temperature should follow the method laid out the in the Euro Inox/ $\mathrm{SCl}$ Design Manual for Structural Stainless Steel (i.e. adopt the room temperature classification, with the $\varepsilon$ factor defined by Eq. (13). Secondly, it was proposed that the strength reduction factor should always be based upon the elevated temperature $0.2 \%$ proof strength for all classes of cross-section. Finally it was proposed to use the room temperature buckling curves from prEN 1993-1-4 (2004) [30] at elevated temperature; this utilises Eq. (8), but now $\varphi_{\theta}$ is defined by Eq. (14).

$$
\varphi_{\theta}=0.5\left(1+\alpha\left(\bar{\lambda}_{\theta}-\bar{\lambda}_{0}\right)+\bar{\lambda}_{\theta}{ }^{2}\right)
$$

where $\alpha$ is the imperfection factor (determined as for room temperature design) and $\bar{\lambda}_{0}$ is the limiting slenderness. For hollow sections, $\alpha$ and $\bar{\lambda}_{0}$ are taken as 0.49 and 0.2 , respectively.

Fig. 9 compares the CTICM/ CSM buckling curve (with $\alpha=0.49$ and $\bar{\lambda}_{0}=0.2$ ) with the test results. The graph shows that for stocky compression members, the test results are generally under-predicted, whilst for slender compression members, the test results are generally over-predicted. The under-prediction for stocky columns is unsurprising, since the design column buckling resistance is restricted by use of the $0.2 \%$ proof strength, whilst the test data indicates that far larger strains can be achieved. The numerical comparisons of Table 8 show a mean CTICM/ CSM divided by test resistance of 1.02, with a corresponding scatter (coefficient of variation, COV) of 0.18. Results of the stub column tests are considered in Table 9, showing a mean CTICM/ CSM divided by test resistance of 0.75 , with a corresponding coefficient of variation (COV) of 0.14 . 
The comparisons between test results and the three design approaches are discussed further in section 5 of this paper.

\subsection{Beams}

From EN 1993-1-2 (2005), the design cross-section bending moment resistance $\mathrm{M}_{\mathrm{fi}, \theta, \mathrm{Rd}}$ of a beam with a uniform temperature $\theta_{\mathrm{a}}$ should be determined from Eq. (15) for Class 1 and 2 cross-sections, Eq. (16) for Class 3 cross-sections and Eq. (17) for Class 4 cross-sections. For Class 1 or 2 cross-sections, plastic section properties are employed with the $2 \%$ strain limit (i.e. adopting $\mathrm{k}_{2, \theta}$ ), for Class 3 cross-sections, elastic section properties are employed with the $2 \%$ strain limit, whilst Class 4 cross-sections utilise the effective section properties (determined as for room temperature design), with the $0.2 \%$ plastic strain limit (i.e. adopting $\mathrm{k}_{0.2 \mathrm{p}, \theta}$ ).

$$
\begin{array}{ll}
M_{\mathrm{fi}, \theta, R d}=k_{2, \theta}\left(\gamma_{\mathrm{MO}} / \gamma_{\mathrm{M}, \mathrm{fi}}\right) M_{\mathrm{pl}, \mathrm{Rd}} & \text { for Class } 1 \text { or } 2 \text { cross-sections } \\
M_{\mathrm{fi}, \theta, \mathrm{Rd}}=\mathrm{k}_{2, \theta}\left(\gamma_{\mathrm{MO}} / \gamma_{\mathrm{M}, \mathrm{fi}}\right) \mathrm{M}_{\mathrm{el}, \mathrm{Rd}} & \text { for Class } 3 \text { cross-sections } \\
M_{\mathrm{fi}, \theta, \mathrm{Rd}}=\mathrm{k}_{0.2 \mathrm{p}, \theta}\left(\gamma_{\mathrm{MO}} / \gamma_{\mathrm{M}, \mathrm{fi}}\right) \mathrm{M}_{\mathrm{eff}, \mathrm{Rd}} & \text { for Class } 4 \text { cross-sections }
\end{array}
$$

The design cross-section bending moment resistance $\mathrm{Mfit}_{\mathrm{f}, \mathrm{Rd}}$ of a beam with a nonuniform temperature distribution at time $t$ is given by Eq. (18).

$$
\mathrm{M}_{\mathrm{fi}, \mathrm{t}, \mathrm{Rd}}=\mathrm{M}_{\mathrm{fi}, \theta, \mathrm{Rd}} / \kappa_{1} \kappa_{2}
$$

Mfi,e,Rd (defined by Eqs. (15) to (17)) is the design moment resistance of the crosssection for a uniform temperature $\theta$ equal to the maximum temperature $\theta$ max (generally at the bottom flange of the beam where the beam supports a concrete slab on the top flange) reached in the cross-section at time t. $\kappa_{1}$ and $\kappa_{2}$ are adaptation factors for nonuniform temperature around the cross-section and along the beam length, respectively. For an unprotected beam, exposed to fire on 3 sides and supporting a 
concrete slab on the fourth, (which was the case for all tested beams considered in this paper), $\kappa_{1}=0.7 . \kappa_{2}$ is taken as 1.0 for all cases other than at the supports of a statically indeterminate beam. It is recommended that the partial safety factors $\gamma \mathrm{m} 1$ and $\gamma_{\mathrm{M}, \mathrm{fi}}$ both be taken equal to unity. Lateral torsional buckling of stainless steel beams in fire has not been considered herein since all tests have been performed on restrained beams.

As for columns, EN 1993-1-2 proposes that cross-sections should be classified based on the room temperature approach, but employing the modified $\varepsilon$ factor given in Eq. (12). The Euro Inox/ SCI Design Manual for Structural Stainless Steel adopts the room temperature cross-section classification for elevated temperature design, but otherwise follows the Eurocode approach. The $\varepsilon$ factor from the Design Manual is defined by Eq. (13). CTICM/ CSM [29] propose no modifications for beams.

A comparison between the design bending moment resistance (at the critical temperature reached in the bottom flange of the beam in the actual fire test) and the applied test bending moment, for each of the beam tests, is given in Table 10. Design bending moment resistance is determined according to EN 1993-1-2 and the Euro Inox/ SCl Design Manual for Structural Stainless Steel. In the comparisons, the measured geometric and material properties are employed and all partial factors are set equal to unity. The comparisons shows a mean predicted divided by test bending moment resistance of 0.74 with a coefficient of variation (COV) of 0.23 for both EN 1993-1-2 and the Euro Inox/ SCI Design Manual for Structural Stainless Steel.

\section{Recommendations for design guidance}

Results from all available tests on stainless steel columns and beams in fire have been compared to existing design guidance given in EN 1993-1-2 [8], the Euro Inox/ SCI Design Manual for Structural Stainless Steel [28] and proposed by CTICM/ CSM [29]. The comparisons given in Tables 8 to 10 generally reveal both conservatism and scatter of prediction in existing design methods, due, in part, to inconsistent treatment 
of buckling and inappropriate strain limits and member buckling curves. Revised recommendations are made herein.

In addition to knowledge of the independent degradation of material strength and stiffness at elevated temperatures, the relationship between strength and stiffness is also important, since this defines susceptibility to buckling. Currently, this concept is included in EN 1993-1-2 and the Euro Inox/ SCI Design Manual for Structural Stainless Steel for member buckling through the definition and use of an elevated temperature non-dimensional member slenderness $\bar{\lambda}_{\theta} . \quad \bar{\lambda}_{\theta}$ is defined by a modification of the room temperature non-dimensional slenderness $\bar{\lambda}$, as given by Eqs. (10) and (11).

The variation of $\left(\mathrm{k}_{\mathrm{E}, \theta} / \mathrm{k}_{2, \theta}\right)^{0.5}$ (where $\mathrm{k}_{2, \theta}$ is based on the $2 \%$ total strain limit) and $\left(\mathrm{k}_{\mathrm{E}, \theta} / \mathrm{k}_{0.2 \mathrm{p}, \theta}\right)^{0.5}$ (where $\mathrm{k}_{0.2 \mathrm{p}, \theta}$ is based on the $0.2 \%$ plastic strain limit) with temperature for stainless steel and carbon steel is shown in Fig. 10. Values of $\left(k_{E, \theta} / k_{2, \theta}\right)^{0.5}$ or $\left(\mathrm{k}_{\mathrm{E}, \theta} / \mathrm{k}_{0.2 \mathrm{p}, \theta}\right)^{0.5}$ less than unity lead to an increase in the non-dimensional member slenderness and represents greater propensity to buckling (rather than yielding) at elevated temperature than at room temperature. For values of $\left(\mathrm{k}_{\mathrm{E}, \theta} / \mathrm{k}_{2, \theta}\right)^{0.5}$ or $\left(\mathrm{k}_{\mathrm{E}, \theta} / \mathrm{k}_{0.2 \mathrm{p}, \theta}\right)^{0.5}$ greater than unity, the reverse is true.

In the treatment of local buckling at room temperature, the $\varepsilon$ factor is employed to allow for variation in material yield strength $f_{y}$. In fire, ENV 1993-1-2 (2001) [31] modified the $\varepsilon$ factor used in section classification to reflect that loss of strength and stiffness at elevated temperatures does not occur at the same rate. Thus, at elevated temperatures $\varepsilon$ was modified by the factor $\left(\mathrm{k}_{\mathrm{E}, \theta} / \mathrm{k}_{2, \theta}\right)^{0.5}$ and was defined by Eq. (19).

$$
\varepsilon=\left[\left(\frac{235}{f_{y}}\right)\left(\frac{k_{E, \theta}}{k_{2, \theta}}\right)\right]^{0.5}
$$


From Fig. 10, it may be seen that for the majority of the elevated temperature range, carbon steel has values of $\left(\mathrm{k}_{\mathrm{E}, \theta} / \mathrm{k}_{2, \theta}\right)^{0.5}$ less than unity and is therefore more susceptible to buckling (as opposed to yielding) than at room temperature; neglecting this feature leads to unsafe predictions. To simplify calculations, this factor was set as a constant of 0.85 (which was deemed an acceptably safe average value at fire limit state) in EN 1993-1-2 (2005) [8], for both carbon steel and stainless steel. Clearly from Fig. 10, however, this factor is inappropriate for stainless steel. The Euro Inox/ $\mathrm{SCl}$ Design Manual for Structural Stainless Steel [28] effectively employs a modification factor of unity by adopting the room temperature classification for elevated temperature. This is more appropriate than the Eurocode 3 treatment, but still, does not correctly reflect the variation of strength and stiffness at elevated temperature exhibited by stainless steel.

It is proposed that the true variation of stiffness and strength at elevated temperature be utilised in cross-section classification and in the determination of effective section properties for stainless steel structures in fire. Thus, the $\varepsilon_{\theta}$ factors defined by Eqs. (20) and (21) should be determined at the critical temperature, and hence used to reclassify the cross-section. Eq. (20) may be applied to cross-sections that are Class 1 or 2 at room temperature and utilises the $2 \%$ strain limit, whilst Eq. (21) applies to cross-sections that are Class 3 or 4 at room temperature and utilises the $0.2 \%$ plastic strain limit. Eq. (21) also applies in the determination of effective section properties. The notation $\varepsilon_{\theta}$ is introduced to differentiate from the $\varepsilon$ factor used for room temperature design.

$$
\begin{aligned}
& \varepsilon_{\theta}=\left[\left(\frac{235}{f_{y}} \frac{E}{210000}\right)\left(\frac{k_{E, \theta}}{k_{2, \theta}}\right)\right]^{0.5}=\varepsilon\left(\frac{k_{E, \theta}}{k_{2, \theta}}\right)^{0.5} \text { for Class } 1 \text { and } 2 \text { sections } \\
& \varepsilon_{\theta}=\left[\left(\frac{235}{f_{y}} \frac{E}{210000}\right)\left(\frac{k_{E, \theta}}{k_{0.2 p, \theta}}\right)\right]^{0.5}=\varepsilon\left(\frac{k_{E, \theta}}{k_{0.2 p, \theta}}\right)^{0.5} \text { for Class } 3 \text { and } 4 \text { sections }
\end{aligned}
$$

From Fig. 10, is may be seen that the factors $\left(k_{E, \theta} / k_{2, \theta}\right)^{0.5}$ and $\left(k_{E, \theta} / k_{0.2 p, \theta}\right)^{0.5}$ for stainless steel are greater than unity at elevated temperatures. The result of cross- 
section re-classification and the re-determination of effective section properties at the critical temperature will therefore be beneficial, and ignoring this process will be conservative. Cross-sections that are Class 4 at room temperature may become fully effective at elevated temperatures.

It is further proposed that in the determination of cross-section and member resistance in fire, the strength reduction factor be based on the $2 \%$ strain limit $\left(k_{2, \theta}\right)$ for Class 1 and 2 cross-sections and the $0.2 \%$ plastic strain limit $\left(k_{0.2 p, \theta}\right)$ for Class 3 and 4 crosssections. Use of the strength at $2 \%$ strain for Class 3 cross-sections, as is proposed in existing design guidance seems unjustified, since local buckling would be expected before this strain level is reached.

Having established a more consistent basis for the treatment of buckling of stainless steel columns and beams in fire, the test results, which were compared against existing design proposals in section 4 of this paper, were re-evaluated. The results have been included in Tables 8 to 10 . For columns, a revised buckling curve has been proposed to provide a mean fit to the test results, which is acceptable at fire limit state. This was achieved by adopting the general form of the room temperature buckling curves of Eq. (8) and (14), and selecting appropriate values of the imperfection parameter $\alpha$ and the limiting slenderness $\bar{\lambda}_{0}$. A comparison of the resulting fire buckling curve with $\alpha=0.55$ and $\bar{\lambda}_{0}=0.2$ is shown in Fig. 11 . Following analysis of the results it was revealed that one the columns, Class 4 at room temperature, becomes Class 2 at elevated temperature, and its resistance is overpredicted by the proposed method. In the absence of further test results, it is recommended that cross-sections that are Class 4 at room temperature cannot be promoted beyond Class 3 at elevated temperatures.

For column buckling, the mean proposed divided by test resistance is 1.00 with a coefficient of variation (COV) of 0.15 . For stub columns, the mean proposed divided by test resistance is 0.91 with a coefficient of variation (COV) of 0.15 , whilst for beams, the mean proposed divided by test resistance is 0.84 with a coefficient of variation (COV) of 0.19 . The proposed treatment offers a more rational approach to the fire design of structural stainless steel columns and beams, yielding an 
improvement of $6 \%$ for column buckling resistance, $28 \%$ for stub column (crosssection) resistance and $14 \%$ for in-plane bending resistance over the current Eurocode methods.

\section{Conclusions}

At elevated temperatures, stainless steel offers better retention of strength and stiffness than structural carbon steel, due to the beneficial effects of the alloying elements. This behaviour is reflected in EN 1993-1-2 (2005). However, in addition to knowledge of the independent degradation of material strength and stiffness at elevated temperatures, the relationship between strength and stiffness is also important, since this defines susceptibility to buckling. This concept has been recognised in EN 1993-1-2 for member buckling by the use of an elevated temperature non-dimensional member slenderness, but for local buckling of stainless steel sections, current codified treatment is inappropriate.

The results of a total of 23 column buckling fire tests, 6 stub column fire tests and 6 fire tests on laterally-restrained beams have been collated and analysed. A selection of the tests have been replicated numerically, where the importance of local and global initial geometric imperfections, residual stresses, enhanced strength corner properties and partial protection of the member ends has been investigated. From the comparisons between test and numerical results, it may be concluded that the described finite element models are capable of replicating the non-linear large deflection response of structural stainless steel members in fire.

A revised buckling curve for stainless steel in fire, consistent strain limits and a new approach to cross-section classification and the treatment of local buckling are proposed. These revisions have led to a more efficient and consistent treatment of buckling of stainless steel columns and beams in fire. Improvements of $6 \%$ for column buckling resistance, $28 \%$ for stub column (cross-section) resistance and 14\% for inplane bending resistance over the current Eurocode methods are achieved. 


\section{Acknowledgements}

The authors would like to thank the Lee Foundation for contributing to the funding of this project, and the Steel Construction Institute for technical input.

\section{References}

[1] Wang, Y. C. (2002). Steel and composite structures - behaviour and design for fire safety. Spon Press.

[2] Buchanan, A. H. (2001). Structural design for fire safety. John Wiley and Sons Ltd.

[3] Lennon, T. and Moore, D. (2003). The natural fire safety concept - full-scale tests at Cardington. Fire Safety Journal. 38(7), 623-643.

[4] Wang, Y. C. (1997). Effects of structural continuity on fire resistant design of steel columns in non-sway multi-storey frames. Fire Safety Journal. 28(2), 101-116

[5] Liu, T. C. H., Fahad, M. K. and Davies, J. M. (2002). Experimental investigation of behaviour of axially restrained steel beams in fire. Journal of Constructional Steel Research. 58(9), 1211-1230.

[6] Bailey, C. G. (2004). Membrane action of slab/beam composite floor systems in fire. Engineering Structures. 26(12), 1691-1703.

[7] Gardner, L. (2005). The use of stainless steel in structures. Progress in Structural Engineering and Materials. 7(2). 45-55.

[8] EN 1993-1-2. (2005). Eurocode 3: Design of steel structures - Part 1.2: General rules Structural fire design. CEN.

[9] Gardner, L. and Ng, K. T. (2006). Temperature development in structural stainless steel sections exposed to fire. Fire Safety Journal. 41(3), 185-203. 
[10] EN 10088-2. (2005). Stainless steels - Part 2: Technical delivery conditions for sheet/plate and strip for general purposes. CEN.

[11] Baddoo, N. R. and Gardner, L. (2000). Member behaviour at elevated temperatures: Work package 5.2. ECSC project 'Development of the use of stainless steel in construction'. Contract No. 7210 SA/842. The Steel Construction Institute, UK.

[12] Gardner, L. and Baddoo, N. R. (2006). Fire testing and design of stainless steel structures. Journal of Constructional Steel Research. 62(6), 532-543.

[13] Ala-Outinen, T. and Oksanen, T. (1997) Stainless steel compression members exposed to fire. VTT Research Notes 1864, Espoo, Finland.

[14] Ala-Outinen, T. (1999). Fire resistance of stainless steel structures. Proceedings of the Second European Conference on Steel Structures (Eurosteel 1999). Prague, Czech Republic, 26th-29th May, 1999. 165-168.

[15] Zhao, B. and Blanguernon, A. (2004). Member Tests in Fire and Structural Fire Design Guidance. Work package 6: Elevated Temperature Properties. ECSC project 'Structural design of cold-worked austenitic stainless steel'. Contract No. 7210-PR-318. The Steel Construction Institute, UK.

[16] Ala-Outinen, T. (2005). Members with Class 4 cross-sections in fire: Work package 3. ECSC project 'Stainless steel in fire (SSIF)'. Contract No. RFS-CR-04048. VTT. (Confidential).

[17] ISO-834-1. (1999). Fire-resistance tests - Elements of building construction - part 1: General requirements. International Organization for Standardization, Geneva.

[18] ABAQUS (2003). ABAQUS/ Standard User's Manual Volumes I-III and ABAQUS CAE Manual. Version 6.4. Hibbitt, Karlsson \& Sorensen, Inc. Pawtucket, USA.

[19] Gardner, L. and Ashraf, M. (2006). Structural design for non-linear metallic materials. Engineering Structures. 28(6), 926-934.

[20] Gardner, L. and Nethercot, D. A. (2004). Numerical modelling of stainless steel structural components - A consistent approach. Journal of Structural Engineering, ASCE. 130(10). 1586-1601. 
[21] Ashraf, M., Gardner, L. and Nethercot, D. A. (2005). Strength enhancement of the corner regions of stainless steel cross-sections. Journal of Constructional Steel Research. 61(1), 3752.

[22] Ala-Outinen, T. (1996). Fire resistance of austenitic stainless steels Polarit 725 (EN 1.4301) and Polarit 761 (EN 1.4571). VTT Research Notes 1760, Espoo, Finland.

[23] Ashraf, M., Gardner, L. and Nethercot, D.A. (2005). Numerical modelling of stainless steel open sections. Proceedings of the Fourth European Conference on Steel and Composite Structures - Eurosteel. 8th-10th June 2005. Maastricht, The Netherlands. 1.2-197-204.

[24] Rasmussen, K. J. R. and Hancock, G. J. (1993). Design of cold-formed stainless steel tubular members. I: Columns. Journal of Structural Engineering, ASCE. 119(8), 2349-2367.

[25] Ellobody, E. and Young, B. (2005). Structural performance of cold-formed high strength stainless steel columns. Journal of Constructional Steel Research. 61(12), 1631-1649.

[26] Dawson, R. G. and Walker, A. C. (1972). Post-buckling of geometrically imperfect plates. Journal of the Structural Division, ASCE. 98(ST1), 75-94.

[27] EN 1991-1-2. (2002). Eurocode 1: Actions on structures - Part 1.2: General actions Actions on structures exposed to fire. CEN.

[28] Euro Inox/ SCl (2002). Design Manual for Structural Stainless Steel. Second edition. Euro Inox and the Steel Construction Institute. Building series, Volume 3.

[29] CTICM/ CSM (2005). Stainless steel column buckling behaviour at elevated temperatures - Comparison of Euro Inox and CTICM methods. Centro Sviluppo Materiali S.p.A.

[30] prEN 1993-1-4. (2004). Eurocode 3: Design of steel structures - Part 1.4: General rules Supplementary rules for stainless steels. CEN.

[31] ENV 1993-1-2. (2001). Eurocode 3: Design of steel structures - Part 1.2: General rules Structural fire design. CEN. 


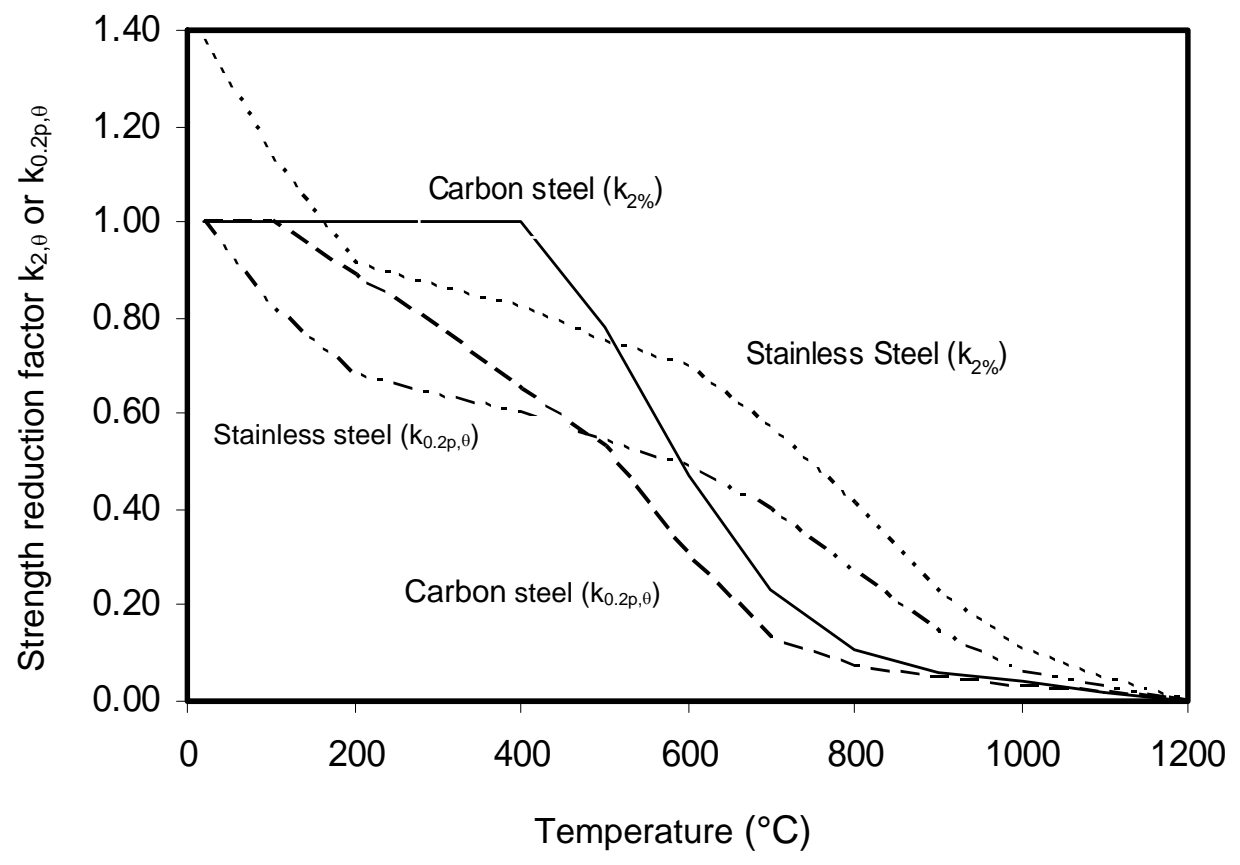

Fig. 1: Comparison of strength reduction at elevated temperatures 


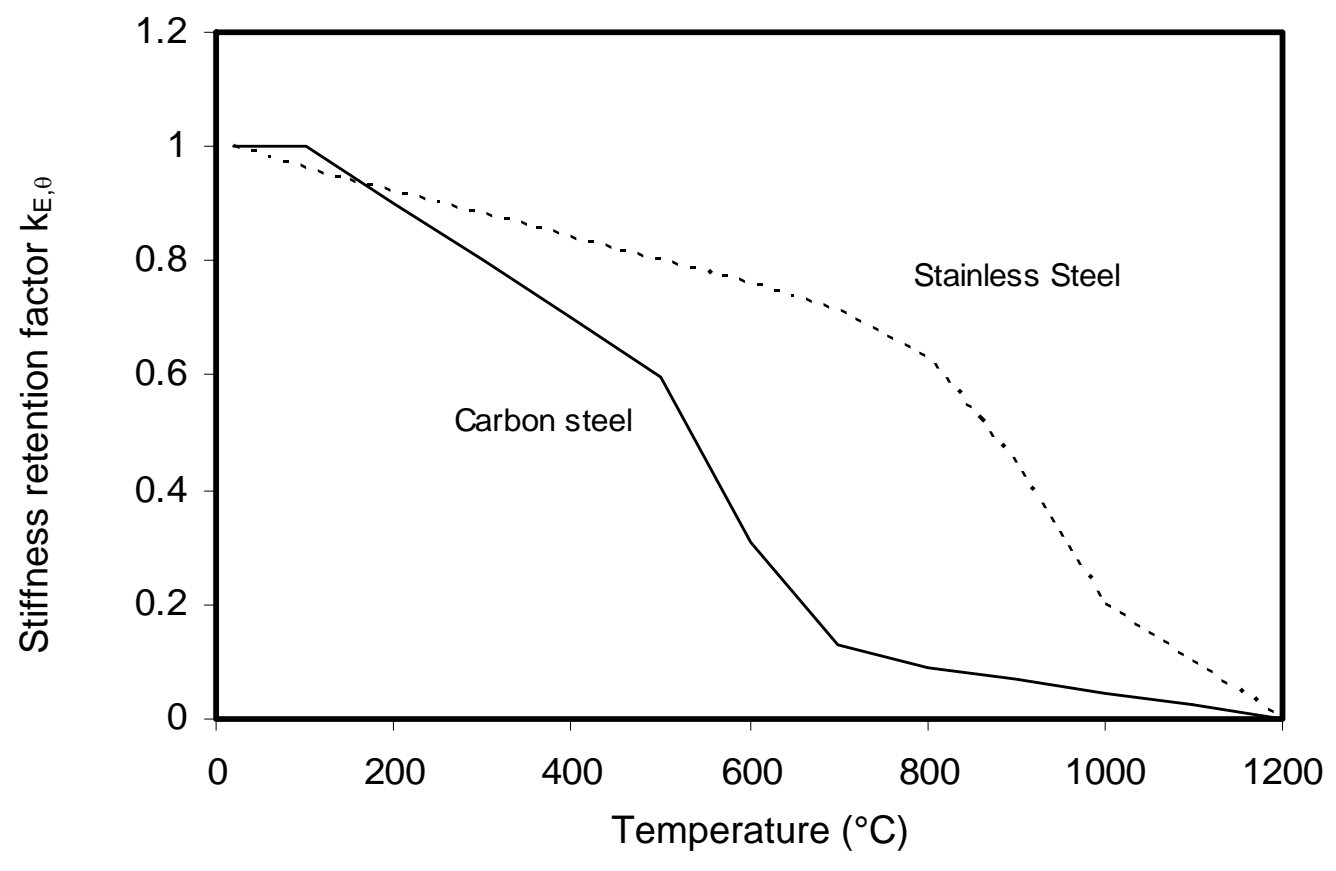

Fig. 2: Comparison of stiffness reduction at elevated temperatures 


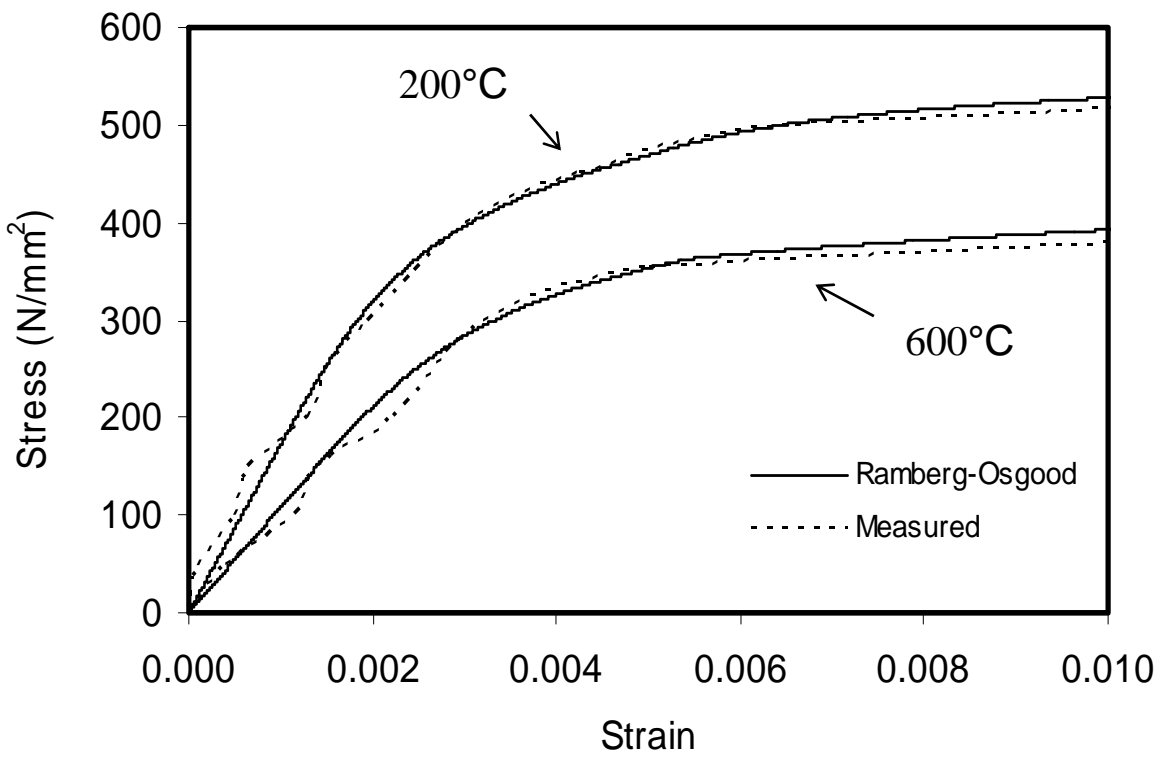

Fig. 3: Stress-strain curves using compound Ramberg-Osgood formulation at elevated temperatures 


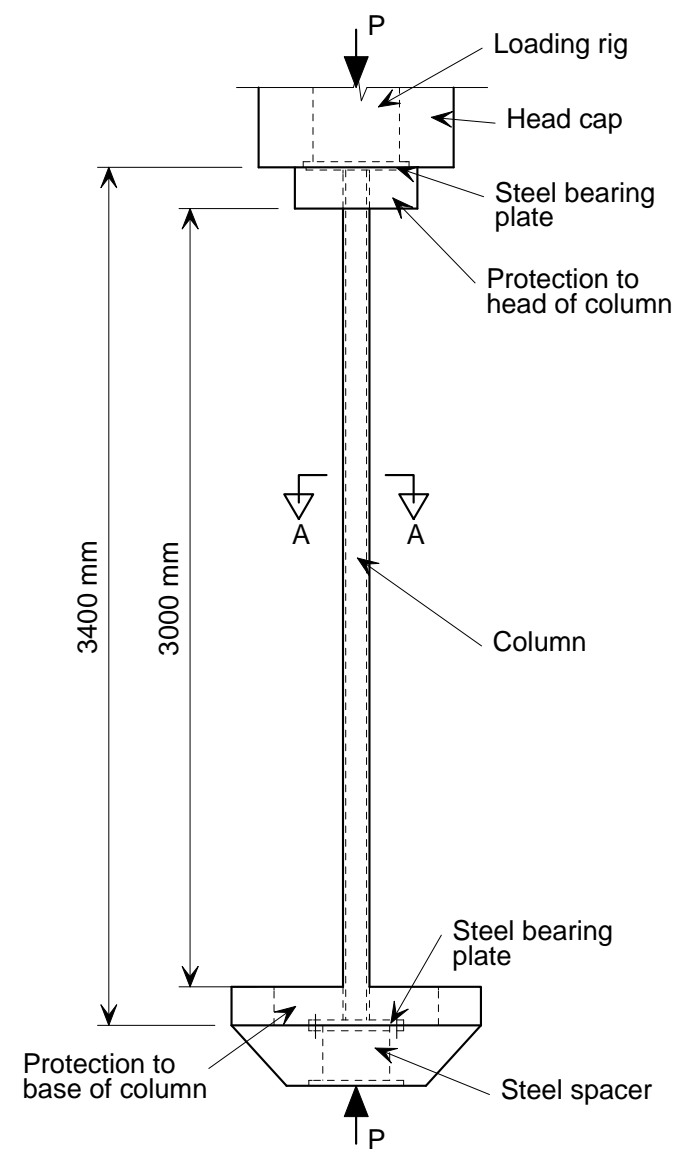

Fig. 4: Test arrangement showing extent of protection to column ends 


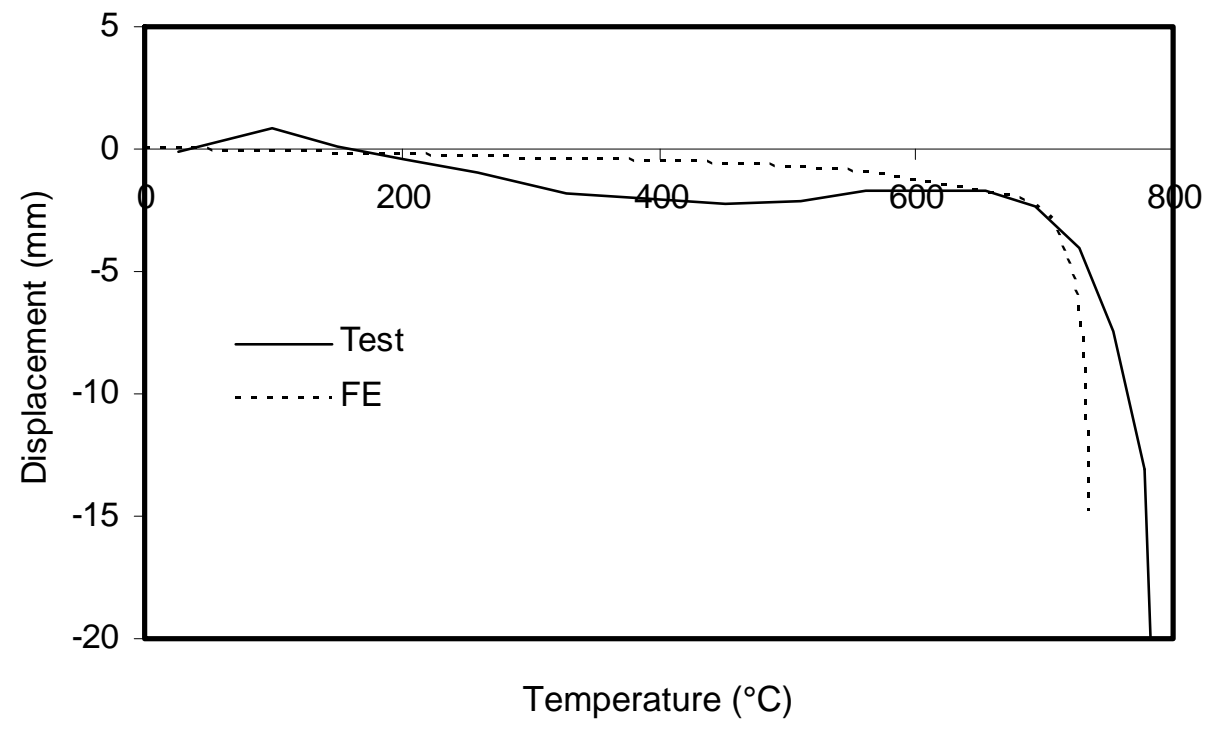

Fig. 5: Lateral displacement versus temperature for RHS 150x100x6 column 


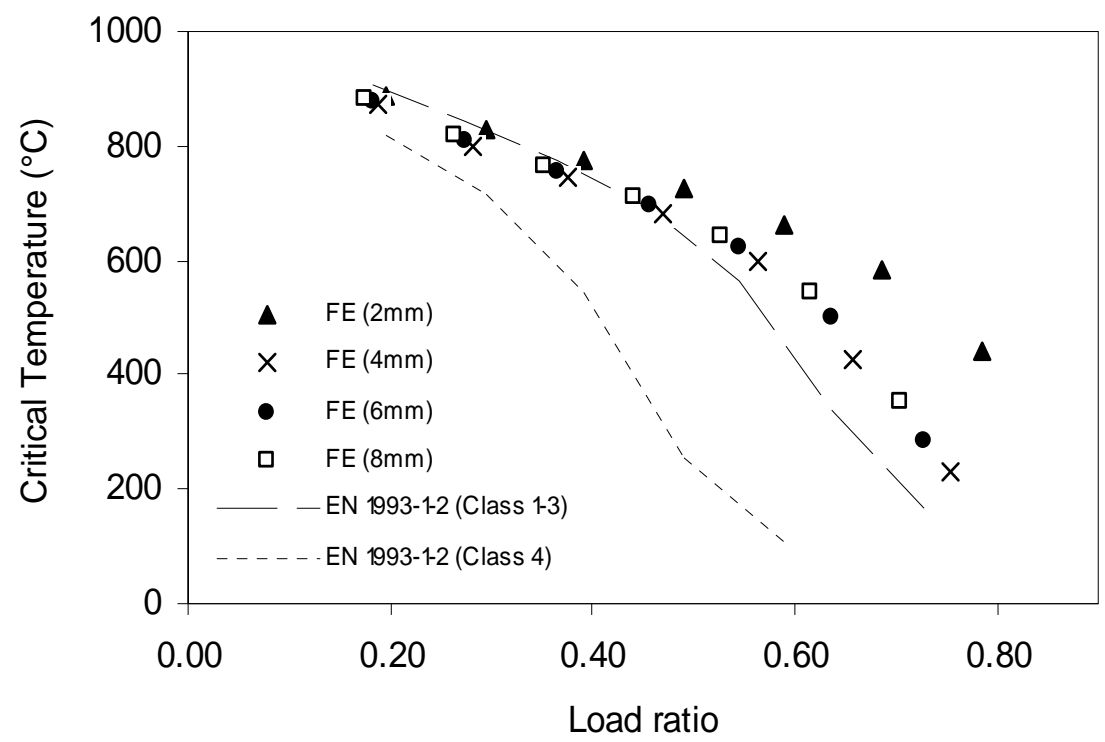

Fig. 6: Parametric study results for varying load ratio and cross-section slenderness 


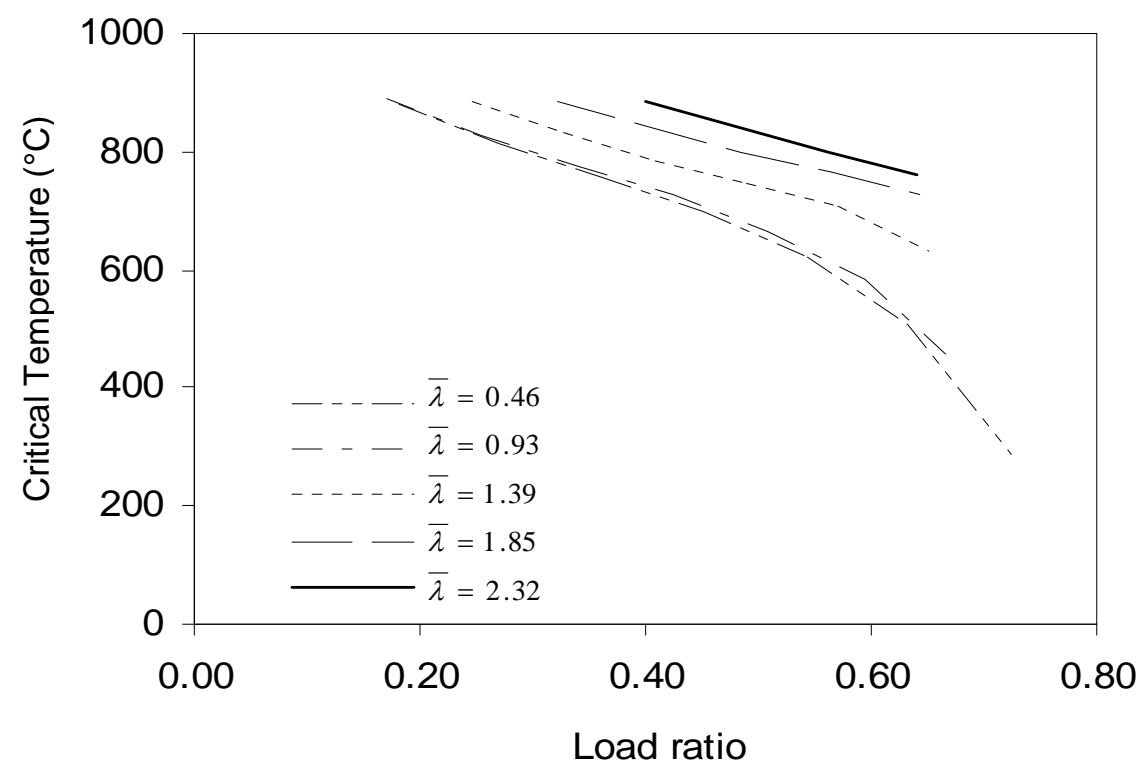

Fig 7: Parametric study results for varying load ratio and member slenderness 


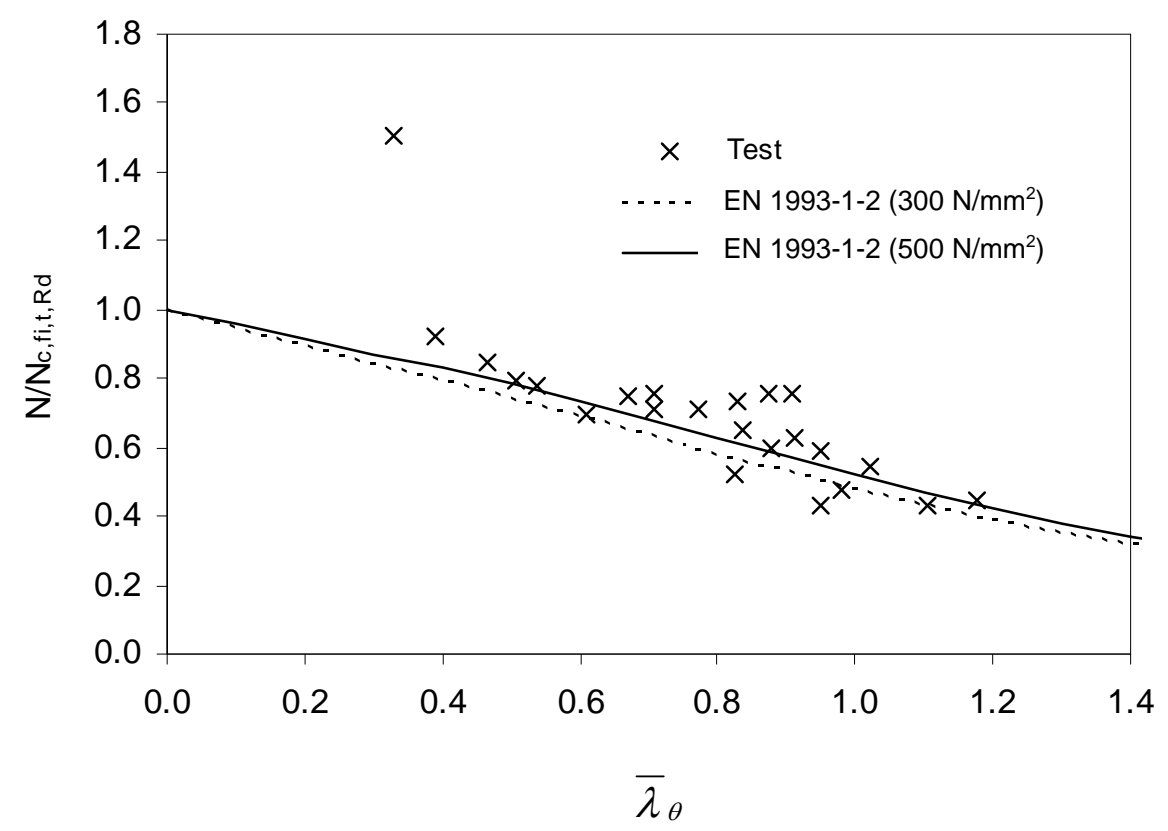

Fig. 8: Comparison of EN 1993-1-2 with column buckling fire tests 


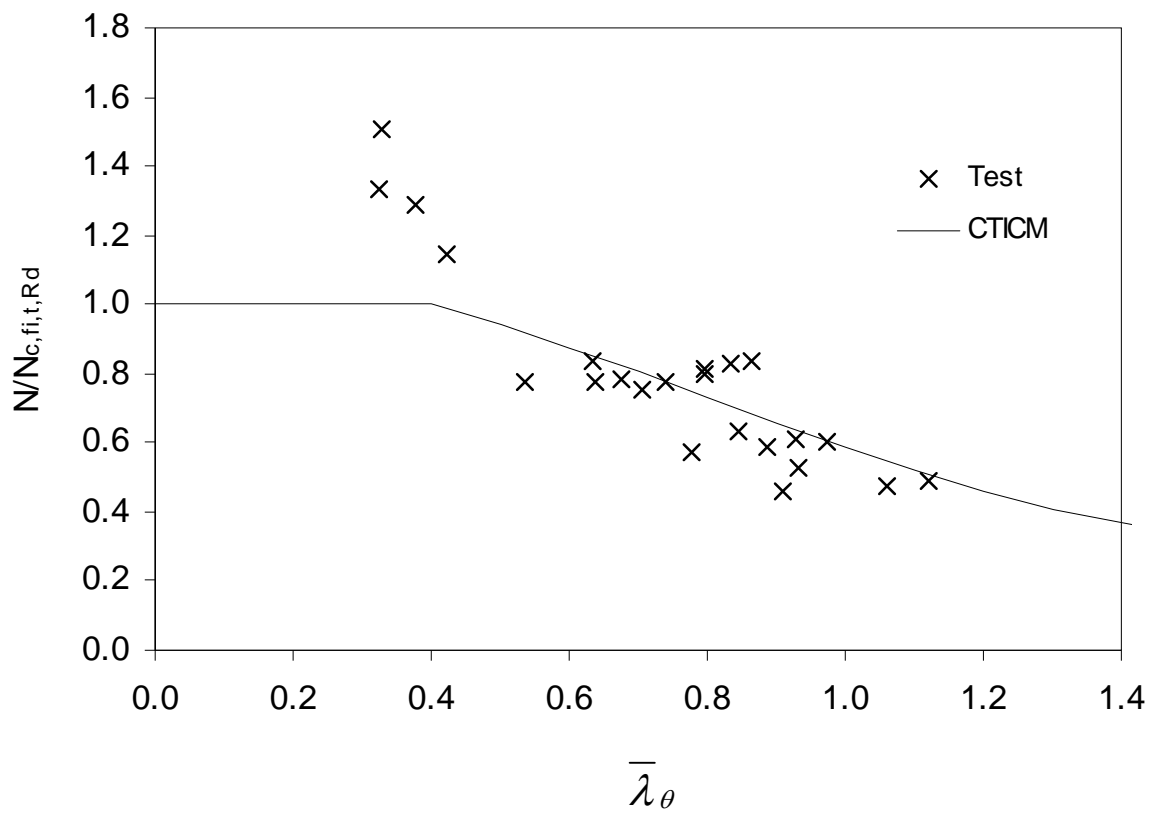

Fig. 9: Comparison of CTICM/ CSM design proposal with column buckling fire tests 


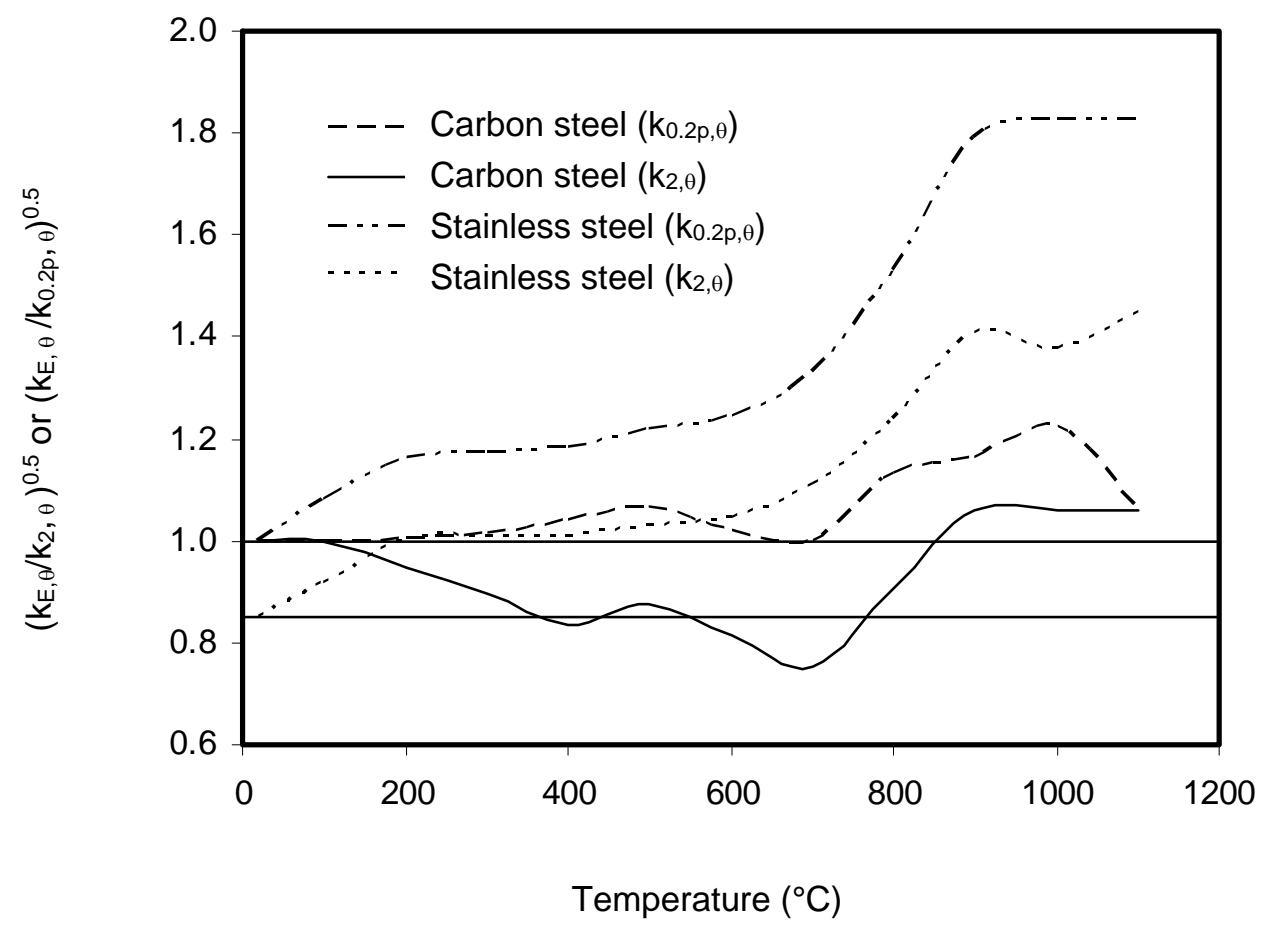

Fig. 10: Variation of the modification factor $\left(k_{E, \theta} / k_{2, \theta}\right)^{0.5}$ and $\left(k_{E, \theta} / k_{0.2 p, \theta}\right)^{0.5}$ with temperature 


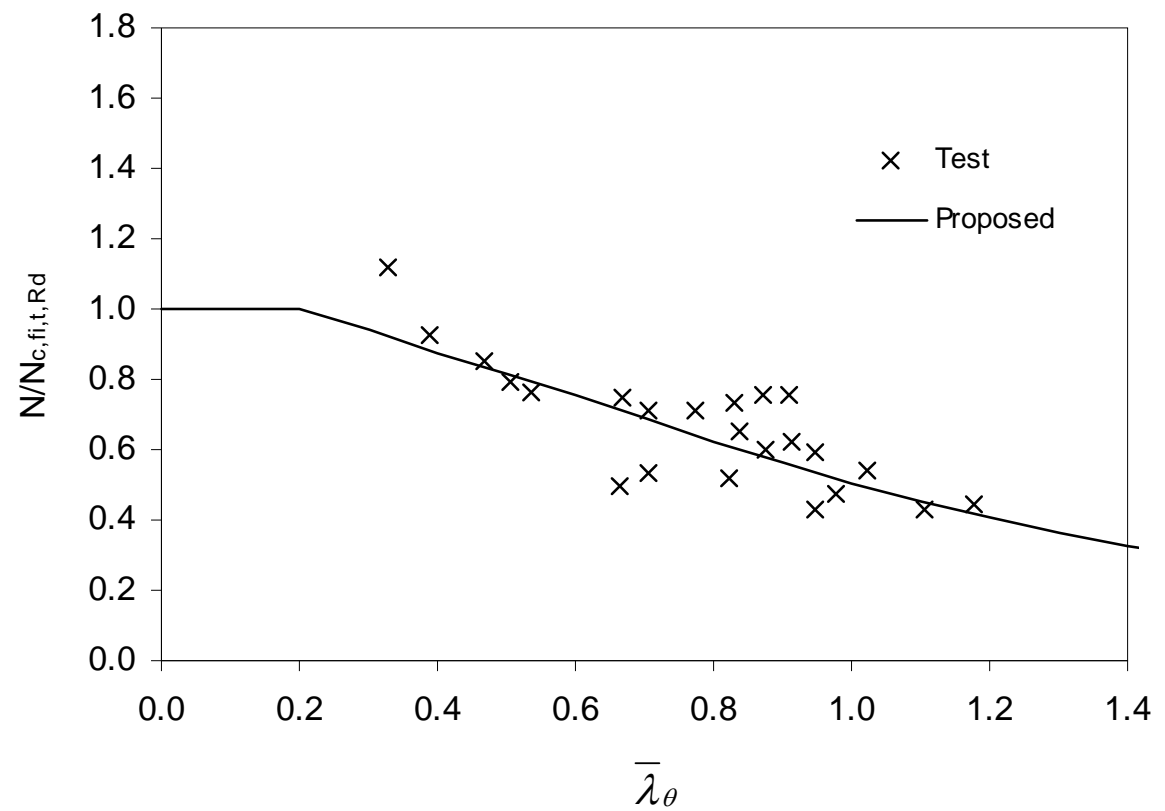

Fig. 11: Comparison of proposed design approach with column buckling fire tests 
Table 1: Summary of tests conducted on structural stainless steel columns

\begin{tabular}{|c|c|c|c|c|c|}
\hline $\begin{array}{l}\text { Nominal section size } \\
(\mathrm{mm})\end{array}$ & $\begin{array}{l}\text { Cross-section } \\
\text { classification }\end{array}$ & $\begin{array}{l}\text { Boundary } \\
\text { conditions }\end{array}$ & $\bar{\lambda}$ & $\begin{array}{l}\text { Applied } \\
\text { load (kN) }\end{array}$ & $\begin{array}{c}\text { Critical } \\
\text { temperature }\left({ }^{\circ} \mathrm{C}\right)\end{array}$ \\
\hline RHS $150 \times 100 \times 6^{a}$ & Class 1 & Fixed & 0.49 & 268 & 801 \\
\hline RHS $150 \times 75 \times 6^{a}$ & Class 1 & Fixed & 0.65 & 140 & 883 \\
\hline RHS $100 \times 75 \times 6^{a}$ & Class 1 & Fixed & 0.65 & 156 & 806 \\
\hline$]\left[200 \times 150 \times 6^{a}\right.$ & Class 4 & Fixed & 0.66 & 413 & 571 \\
\hline RHS $100 \times 100 \times 4^{a}$ & Class 2 & Pinned & 1.27 & 80 & 835 \\
\hline RHS $200 \times 200 \times 4^{a}$ & Class 4 & Pinned & 0.51 & 230 & 820 \\
\hline RHS $40 \times 40 \times 4(T 1)^{b}$ & Class 1 & Pinned & 1.07 & 45 & 873 \\
\hline RHS $40 \times 40 \times 4(T 2)^{b}$ & Class 1 & Pinned & 1.07 & 129 & 579 \\
\hline RHS $40 \times 40 \times 4(T 3)^{b}$ & Class 1 & Pinned & 1.07 & 114 & 649 \\
\hline RHS $40 \times 40 \times 4(T 4)^{b}$ & Class 1 & Pinned & 1.07 & 95 & 710 \\
\hline RHS $40 \times 40 \times 4(T 5)^{b}$ & Class 1 & Pinned & 1.07 & 55 & 832 \\
\hline RHS $40 \times 40 \times 4(T 7)^{b}$ & Class 1 & Pinned & 1.07 & 75 & 766 \\
\hline RHS $40 \times 40 \times 4^{c}$ & Class 1 & Pinned & 1.02 & 102 & 720 \\
\hline RHS $40 \times 40 \times 4^{c}$ & Class 1 & Pinned & 1.02 & 73 & 834 \\
\hline RHS $40 \times 40 \times 4^{c}$ & Class 1 & Pinned & 1.02 & 63 & 873 \\
\hline RHS $30 \times 30 \times 3^{c}$ & Class 1 & Pinned & 1.40 & 41 & 610 \\
\hline RHS $30 \times 30 \times 3^{c}$ & Class 1 & Pinned & 1.40 & 33 & 693 \\
\hline RHS $30 \times 30 \times 3^{c}$ & Class 1 & Pinned & 1.40 & 21 & 810 \\
\hline $\mathrm{CHS} 33.7 \times 2^{\mathrm{c}}$ & Class 1 & Pinned & 1.26 & 26 & 668 \\
\hline $\mathrm{CHS} 33.7 \times 2^{\mathrm{c}}$ & Class 1 & Pinned & 1.26 & 12 & 850 \\
\hline $\mathrm{CHS} 33.7 \times 2^{\mathrm{c}}$ & Class 1 & Pinned & 1.26 & 20 & 716 \\
\hline RHS $100 \times 100 \times 3^{d}$ & Class 4 & Pinned & 1.02 & 52 & 835 \\
\hline RHS $100 \times 100 \times 3^{d}$ & Class 4 & Pinned & 1.20 & 52 & 880 \\
\hline
\end{tabular}

Notes: ${ }^{a}$ Tests reported in [5] and [6] and replicated numerically in section 3

b Tests reported in [7] and replicated numerically in section 3

${ }^{\mathrm{c}}$ Tests reported in [8]

${ }^{\mathrm{d}}$ Tests reported in [9] 
Table 2: Summary of tests conducted on structural stainless steel stub columns

\begin{tabular}{|c|c|c|c|c|}
\hline $\begin{array}{l}\text { Nominal section size } \\
(\mathrm{mm})\end{array}$ & $\begin{array}{l}\text { Cross-section } \\
\text { classification }\end{array}$ & $\begin{array}{l}\text { Boundary } \\
\text { conditions }\end{array}$ & $\begin{array}{l}\text { Applied } \\
\text { load (kN) }\end{array}$ & $\begin{array}{c}\text { Critical } \\
\text { temperature }\left({ }^{\circ} \mathrm{C}\right)\end{array}$ \\
\hline RHS $200 \times 200 \times 5$ & Class 4 & Fixed & 694 & 609 \\
\hline RHS $200 \times 200 \times 5$ & Class 4 & Fixed & 567 & 685 \\
\hline RHS $200 \times 200 \times 5$ & Class 4 & Fixed & 463 & 768 \\
\hline RHS $150 \times 150 \times 3$ & Class 4 & Fixed & 248 & 590 \\
\hline RHS $150 \times 150 \times 3$ & Class 4 & Fixed & 203 & 678 \\
\hline RHS $150 \times 150 \times 3$ & Class 4 & Fixed & 165 & 720 \\
\hline
\end{tabular}


Table 3: Summary of tests conducted on structural stainless steel beams

\begin{tabular}{|l|c|c|c|c|}
\hline $\begin{array}{l}\text { Nominal section size } \\
(\mathrm{mm})\end{array}$ & $\begin{array}{c}\text { Cross-section } \\
\text { classification }\end{array}$ & $\begin{array}{c}\text { Boundary } \\
\text { conditions }\end{array}$ & $\begin{array}{c}\text { Applied load } \\
(\mathrm{kN})\end{array}$ & $\begin{array}{c}\text { Critical } \\
\text { temperature }\left({ }^{\circ} \mathrm{C}\right)\end{array}$ \\
\hline RHS $200 \times 125 \times 6^{\mathrm{a}}$ & Class 1 & Simply supported & 52.3 & 884 \\
]$\left[\left[200 \times 150 \times 6^{\mathrm{a}}\right.\right.$ & Class 4 & Simply supported & 32.4 & 944 \\
]$\left[\left[120 \times 64^{\mathrm{a}}\right.\right.$ & Class 1 & Simply supported & 47.0 & 650 \\
]$\left[\left[120 \times 64^{\mathrm{a}}\right.\right.$ & Class 1 & Continuous & 39.9 & 840 \\
\hline Top hat $100 \times 100 \times 2^{\mathrm{d}}$ & Class 4 & Simply supported & 5.0 & 880 \\
Top hat $100 \times 100 \times 2^{\mathrm{d}}$ & Class 4 & Simply supported & 9.2 & 765 \\
\hline
\end{tabular}

Notes: ${ }^{a}$ Tests reported in [5] and [6]

${ }^{\mathrm{d}}$ Tests reported in [9] 
Table 4: Comparison of critical temperature of FE under different corner properties with the tests

\begin{tabular}{|c|c|c|c|c|c|}
\hline \multirow{2}{*}{$\begin{array}{l}\text { Nominal section size } \\
(\mathrm{mm})\end{array}$} & \multirow{2}{*}{$\begin{array}{c}\text { Measured } \\
\sigma_{0.2, \mathrm{f}}\end{array}$} & \multirow{2}{*}{$\begin{array}{c}\text { Calculated } \\
\sigma_{0.2, \mathrm{c}}\end{array}$} & \multicolumn{3}{|c|}{ Critical Temperature } \\
\hline & & & FE/Test & $\mathrm{FE}(\mathrm{c}) /$ Test & $\mathrm{FE}_{(\mathrm{c}+\mathrm{t})} / \mathrm{Test}$ \\
\hline RHS $150 \times 100 \times 6$ & 262 & 524.9 & 0.86 & 0.89 & 0.92 \\
\hline RHS $150 \times 75 \times 6$ & 262 & 524.9 & 0.90 & 0.91 & 0.93 \\
\hline RHS $100 \times 75 \times 6$ & 262 & 524.4 & 0.89 & 0.93 & 0.94 \\
\hline$][200 \times 150 \times 6$ & 262 & 524.4 & 1.03 & 1.06 & 1.16 \\
\hline & & Mean & 0.92 & 0.95 & 0.98 \\
\hline
\end{tabular}

Notes: FE - No strength enhancements included in corner regions

$\mathrm{FE}_{(\mathrm{c})}$ - Strength enhancements in curved corner regions of the cross-section

$\mathrm{FE}_{(\mathrm{c}+\mathrm{t})}$ - Corner strength enhancements in curved corner regions of the cross-section and extending to a distance equal to the material thickness beyond the corners 
Table 5: Comparison of critical temperature and fire resistant time of FE with tests under different global imperfection amplitude

\begin{tabular}{|c|c|c|c|c|c|c|}
\hline \multirow{3}{*}{$\begin{array}{l}\text { Nominal section size } \\
(\mathrm{mm})\end{array}$} & \multicolumn{6}{|c|}{ FE/ Test } \\
\hline & \multicolumn{2}{|c|}{$\delta=L / 2000$} & \multicolumn{2}{|c|}{$\delta=\mathrm{L} / 1000$} & \multicolumn{2}{|c|}{$\delta=\mathrm{L} / 500$} \\
\hline & Time & Temp. & Time & Temp. & Time & Temp. \\
\hline RHS $150 \times 100 \times 6$ & 0.81 & 0.90 & 0.78 & 0.89 & 0.75 & 0.87 \\
\hline RHS $150 \times 75 \times 6$ & 0.73 & 0.92 & 0.71 & 0.91 & 0.69 & 0.90 \\
\hline RHS $100 \times 75 \times 6$ & 0.78 & 0.91 & 0.75 & 0.90 & 0.72 & 0.89 \\
\hline$][200 \times 150 \times 6$ & 1.14 & 1.09 & 1.14 & 1.06 & 0.93 & 0.98 \\
\hline RHS $100 \times 100 \times 4$ & 0.67 & 0.89 & 0.74 & 0.91 & 0.74 & 0.91 \\
\hline RHS $200 \times 200 \times 4$ & 0.58 & 0.85 & 0.58 & 0.85 & 0.58 & 0.85 \\
\hline RHS $40 \times 40 \times 4(T 1)$ & 1.00 & 0.84 & 1.00 & 0.84 & 0.99 & 0.83 \\
\hline RHS $40 \times 40 \times 4(T 2)$ & 0.90 & 0.87 & 0.76 & 0.72 & 0.57 & 0.49 \\
\hline RHS $40 \times 40 \times 4$ (T3) & 0.94 & 0.92 & 0.90 & 0.87 & 0.81 & 0.78 \\
\hline RHS $40 \times 40 \times 4(T 4)$ & 0.94 & 0.89 & 0.93 & 0.88 & 0.91 & 0.86 \\
\hline RHS $40 \times 40 \times 4$ (T5) & 0.92 & 0.87 & 0.91 & 0.85 & 0.90 & 0.84 \\
\hline RHS $40 \times 40 \times 4(T 7)$ & 0.85 & 0.88 & 0.84 & 0.87 & 0.83 & 0.86 \\
\hline Mean & 0.85 & 0.90 & 0.84 & 0.88 & 0.78 & 0.84 \\
\hline
\end{tabular}


Table 6: Comparison of critical temperature of FE with and without end protection with the tests

\begin{tabular}{|c|c|c|}
\hline \multirow{2}{*}{$\begin{array}{l}\text { Nominal section size } \\
(\mathrm{mm})\end{array}$} & \multicolumn{2}{|c|}{ Critical temperature } \\
\hline & FE/ Test & FEp/ Test \\
\hline RHS $150 \times 100 \times 6$ & 0.92 & 0.93 \\
\hline RHS $150 \times 75 \times 6$ & 0.93 & 0.95 \\
\hline RHS $100 \times 75 \times 6$ & 0.94 & 0.98 \\
\hline$][200 \times 150 \times 6$ & 1.16 & 1.21 \\
\hline Mean & 0.98 & 1.02 \\
\hline
\end{tabular}

Notes: FE - Model without end protection

$\mathrm{FE}_{\mathrm{p}}$ - Model with end protection 
Table 7: Comparison of fire resistance (time) and critical temperature between test and FE results

\begin{tabular}{|c|c|c|c|c|c|c|}
\hline \multirow{2}{*}{$\begin{array}{l}\text { Nominal section size } \\
(\mathrm{mm})\end{array}$} & \multicolumn{2}{|c|}{ Test } & \multicolumn{2}{|c|}{ FE } & \multicolumn{2}{|c|}{ FE/ Test } \\
\hline & $\begin{array}{c}\text { Time } \\
\text { (minutes) }\end{array}$ & $\begin{array}{l}\text { Temp. } \\
\left({ }^{\circ} \mathrm{C}\right)\end{array}$ & $\begin{array}{c}\text { Time } \\
\text { (minutes) }\end{array}$ & $\begin{array}{l}\text { Temp. } \\
\left({ }^{\circ} \mathrm{C}\right)\end{array}$ & Time & Temp. \\
\hline RHS $150 \times 100 \times 6$ & 32 & 801 & 28 & 734 & 0.88 & 0.92 \\
\hline RHS $150 \times 75 \times 6$ & 51 & 883 & 39 & 819 & 0.76 & 0.93 \\
\hline RHS $100 \times 75 \times 6$ & 36 & 806 & 29 & 754 & 0.81 & 0.94 \\
\hline$][200 \times 150 \times 6$ & 14 & 571 & 18 & 661 & 1.29 & 1.16 \\
\hline RHS $100 \times 100 \times 4$ & 27 & 835 & 18 & 747 & 0.67 & 0.89 \\
\hline RHS $200 \times 200 \times 4$ & 24 & 820 & 14 & 696 & 0.58 & 0.85 \\
\hline RHS 40×40×4 (T1) & 135 & 873 & 135 & 736 & 1.00 & 0.84 \\
\hline RHS 40×40×4 (T2) & 107 & 579 & 96 & 505 & 0.90 & 0.87 \\
\hline RHS $40 \times 40 \times 4$ (T3) & 120 & 649 & 113 & 597 & 0.94 & 0.92 \\
\hline RHS $40 \times 40 \times 4(T 4)$ & 127 & 710 & 119 & 633 & 0.94 & 0.89 \\
\hline RHS 40×40×4 (T5) & 141 & 832 & 130 & 720 & 0.92 & 0.87 \\
\hline RHS 40×40×4 (T7) & 146 & 766 & 124 & 675 & 0.85 & 0.88 \\
\hline & & & & Mean & 0.88 & 0.91 \\
\hline
\end{tabular}


Table 8: Comparison of column buckling test results with existing design guidance and proposed approach

\begin{tabular}{|c|c|c|c|c|c|c|c|c|c|}
\hline \multirow{2}{*}{$\begin{array}{l}\text { Nominal section size } \\
(\mathrm{mm})\end{array}$} & \multirow{2}{*}{$\begin{array}{l}\text { Applied } \\
\text { Load } \\
\text { (kN) }\end{array}$} & \multirow{2}{*}{$\begin{array}{c}\text { Test critical } \\
\text { temperature } \\
\left({ }^{\circ} \mathrm{C}\right)\end{array}$} & \multirow{2}{*}{$\begin{array}{c}\text { Room } \\
\text { temperature } \\
\text { classification } \\
\text { (EN 1993) }\end{array}$} & \multirow{2}{*}{$\begin{array}{c}\text { Elevated } \\
\text { temperature } \\
\text { classification } \\
\text { (EN 1993) }\end{array}$} & \multirow{2}{*}{$\begin{array}{l}\text { Elevated } \\
\text { temperature } \\
\text { classification } \\
\text { (Proposed) }\end{array}$} & \multicolumn{4}{|c|}{ Buckling resistance at critical temperature } \\
\hline & & & & & & $\begin{array}{c}\text { EN 1993/ } \\
\text { Test }\end{array}$ & $\begin{array}{l}\text { Euro Inox/ } \\
\text { Test }\end{array}$ & $\begin{array}{l}\text { CTICM/ } \\
\text { Test }\end{array}$ & $\begin{array}{l}\text { Proposed/ } \\
\text { Test }\end{array}$ \\
\hline RHS $150 \times 100 \times 6$ & 268 & 801 & Class 1 & Class 3 & Class 1 & 0.85 & 0.85 & 0.75 & 0.97 \\
\hline RHS $150 \times 75 \times 6$ & 140 & 883 & Class 1 & Class 3 & Class 1 & 0.88 & 0.88 & 0.78 & 1.00 \\
\hline RHS $100 \times 75 \times 6$ & 156 & 806 & Class 1 & Class 1 & Class 1 & 0.91 & 0.91 & 0.86 & 1.03 \\
\hline$][200 \times 150 \times 6$ & 413 & 571 & Class 4 & Class 4 & Class 3 & 0.91 & 0.91 & 1.18 & 1.06 \\
\hline RHS $100 \times 100 \times 4$ & 80 & 835 & Class 2 & Class 3 & Class 1 & 0.83 & 0.83 & 0.90 & 0.91 \\
\hline RHS $200 \times 200 \times 4$ & 230 & 820 & Class 4 & Class 4 & Class 4 & 0.55 & 0.55 & 0.67 & 0.83 \\
\hline RHS $40 \times 40 \times 4(T 1)$ & 45 & 873 & Class 1 & Class 1 & Class 1 & 0.96 & 0.96 & 1.02 & 0.96 \\
\hline RHS $40 \times 40 \times 4(T 2)$ & 129 & 579 & Class 1 & Class 1 & Class 1 & 0.77 & 0.77 & 0.81 & 0.76 \\
\hline RHS $40 \times 40 \times 4(T 3)$ & 114 & 649 & Class 1 & Class 1 & Class 1 & 0.80 & 0.80 & 0.85 & 0.79 \\
\hline RHS $40 \times 40 \times 4(T 4)$ & 95 & 710 & Class 1 & Class 1 & Class 1 & 0.85 & 0.85 & 0.92 & 0.85 \\
\hline RHS $40 \times 40 \times 4$ (T5) & 55 & 832 & Class 1 & Class 1 & Class 1 & 0.96 & 0.96 & 1.05 & 0.98 \\
\hline RHS $40 \times 40 \times 4(T 7)$ & 75 & 766 & Class 1 & Class 1 & Class 1 & 0.92 & 0.92 & 1.00 & 0.92 \\
\hline RHS $40 \times 40 \times 4$ & 102 & 720 & Class 1 & Class 1 & Class 1 & 0.94 & 0.94 & 1.04 & 0.93 \\
\hline RHS $40 \times 40 \times 4$ & 73 & 834 & Class 1 & Class 1 & Class 1 & 0.99 & 0.99 & 1.14 & 0.99 \\
\hline RHS $40 \times 40 \times 4$ & 63 & 873 & Class 1 & Class 1 & Class 1 & 0.95 & 0.95 & 1.10 & 0.95 \\
\hline RHS $30 \times 30 \times 3$ & 41 & 610 & Class 1 & Class 1 & Class 1 & 1.00 & 1.00 & 1.03 & 0.95 \\
\hline RHS $30 \times 30 \times 3$ & 33 & 693 & Class 1 & Class 1 & Class 1 & 1.12 & 1.12 & 1.15 & 1.09 \\
\hline RHS $30 \times 30 \times 3$ & 21 & 810 & Class 1 & Class 1 & Class 1 & 1.31 & 1.31 & 1.41 & 1.31 \\
\hline CHS $33.7 \times 2$ & 26 & 668 & Class 1 & Class 1 & Class 1 & 0.92 & 0.92 & 1.00 & 0.92 \\
\hline CHS $33.7 \times 2$ & 12 & 850 & Class 1 & Class 1 & Class 1 & 1.17 & 1.17 & 1.25 & 1.17 \\
\hline $\mathrm{CHS} 33.7 \times 2$ & 20 & 716 & Class 1 & Class 1 & Class 1 & 1.10 & 1.10 & 1.20 & 1.10 \\
\hline RHS $100 \times 100 \times 3$ & 52 & 835 & Class 4 & Class 4 & Class $3^{a}$ & 1.02 & 1.02 & 1.25 & 1.31 \\
\hline RHS $100 \times 100 \times 3$ & 52 & 880 & Class 4 & Class 4 & Class 4 & 0.92 & 0.92 & 1.06 & 1.33 \\
\hline & & & & & Mean & 0.94 & 0.94 & 1.02 & 1.00 \\
\hline & & & & & cov & 0.16 & 0.16 & 0.18 & 0.15 \\
\hline
\end{tabular}

Note: ${ }^{a}$ Cross-section classification limited to Class 3 
Table 9: Comparison of stub column test results with existing design guidance and proposed approach

\begin{tabular}{|c|c|c|c|c|c|c|}
\hline \multirow{2}{*}{$\begin{array}{l}\text { Nominal section } \\
\text { size }(\mathrm{mm})\end{array}$} & \multirow{2}{*}{$\begin{array}{l}\text { Applied } \\
\text { load (kN) }\end{array}$} & \multirow{2}{*}{$\begin{array}{c}\text { Test critical } \\
\text { temperature } \\
\left({ }^{\circ} \mathrm{C}\right)\end{array}$} & \multicolumn{4}{|c|}{ Stub column resistance at critical temperature } \\
\hline & & & $\begin{array}{c}\text { EN 1993/ } \\
\text { Test }\end{array}$ & $\begin{array}{l}\text { Euro Inox/ } \\
\text { Test }\end{array}$ & $\begin{array}{l}\text { CTICM/ } \\
\text { Test }\end{array}$ & $\begin{array}{c}\text { Proposed/ } \\
\text { Test }\end{array}$ \\
\hline RHS $200 \times 200 \times 5$ & 694 & 609 & 0.63 & 0.63 & 0.66 & 0.76 \\
\hline RHS $200 \times 200 \times 5$ & 567 & 685 & 0.66 & 0.66 & 0.69 & 0.83 \\
\hline RHS $200 \times 200 \times 5$ & 463 & 768 & 0.61 & 0.61 & 0.64 & 0.81 \\
\hline RHS $150 \times 150 \times 3$ & 248 & 590 & 0.75 & 0.75 & 0.79 & 0.93 \\
\hline RHS $150 \times 150 \times 3$ & 203 & 678 & 0.77 & 0.77 & 0.82 & 1.00 \\
\hline \multirow[t]{3}{*}{ RHS $150 \times 150 \times 3$} & 165 & 720 & 0.85 & 0.85 & 0.90 & 1.13 \\
\hline & & Mean & 0.71 & 0.71 & 0.75 & 0.91 \\
\hline & & COV & 0.13 & 0.13 & 0.14 & 0.15 \\
\hline
\end{tabular}


Table 10: Comparison of beam test results with existing design guidance and proposed approach

\begin{tabular}{|c|c|c|c|c|c|c|c|c|}
\hline \multirow{2}{*}{$\begin{array}{l}\text { Nominal section size } \\
(\mathrm{mm})\end{array}$} & \multirow{2}{*}{$\begin{array}{c}\text { Test } \\
\text { moment } \\
(\mathrm{kNm})\end{array}$} & \multirow{2}{*}{$\begin{array}{c}\text { Test critical } \\
\text { temperature } \\
\left({ }^{\circ} \mathrm{C}\right)\end{array}$} & \multirow{2}{*}{$\begin{array}{c}\text { Room } \\
\text { temperature } \\
\text { classification } \\
\text { (EN 1993) }\end{array}$} & \multirow{2}{*}{$\begin{array}{c}\text { Elevated } \\
\text { temperature } \\
\text { classification } \\
\text { (EN 1993) }\end{array}$} & \multirow{2}{*}{$\begin{array}{c}\text { Elevated } \\
\text { temperature } \\
\text { classification } \\
\text { (Proposed) }\end{array}$} & \multicolumn{3}{|c|}{$\begin{array}{l}\text { Bending resistance at critical } \\
\text { temperature }\end{array}$} \\
\hline & & & & & & $\begin{array}{l}\text { EN 1993/ } \\
\text { Test }\end{array}$ & $\begin{array}{l}\text { Euro Inox/ } \\
\text { Test }\end{array}$ & $\begin{array}{l}\text { Proposed/ } \\
\text { Test }\end{array}$ \\
\hline RHS $200 \times 125 \times 6$ & 27.8 & 884 & Class 1 & Class 1 & Class 1 & 0.85 & 0.85 & 0.85 \\
\hline$][200 \times 150 \times 6$ & 17.2 & 944 & Class 4 & Class 4 & Class $3^{a}$ & 0.53 & 0.53 & 0.55 \\
\hline$][120 \times 64$ & 15.2 & 650 & Class 1 & Class 1 & Class 1 & 0.97 & 0.97 & 0.97 \\
\hline$][120 \times 64$ & 8.9 & 840 & Class 1 & Class 1 & Class 1 & 0.85 & 0.85 & 0.85 \\
\hline Top hat $100 \times 100 \times 2$ & 2.38 & 880 & Class 4 & Class 4 & Class 3 & 0.56 & 0.56 & 0.82 \\
\hline Top hat $100 \times 100 \times 2$ & 4.37 & 765 & Class 4 & Class 4 & Class 4 & 0.71 & 0.71 & 0.99 \\
\hline & & & & & Mean & 0.74 & 0.74 & 0.84 \\
\hline & & & & & cov & 0.23 & 0.23 & 0.19 \\
\hline
\end{tabular}

Note: ${ }^{a}$ Cross-section classification limited to Class 3 